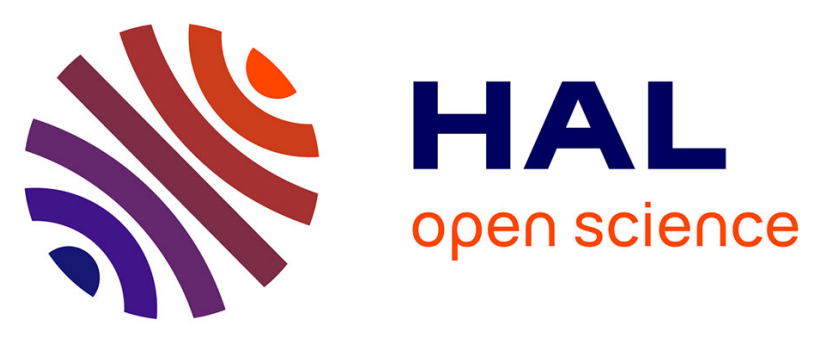

\title{
Designing the 3D Architecture of PGM-Free Cathodes for H 2 /Air Proton Exchange Membrane Fuel Cells
} Jingkun Li, Sebastian Brüller, Dinesh Sabarirajan, Nastaran Ranjbar-Sahraie, Moulay Tahar Sougrati, Sara Cavaliere, Deborah Jones, Iryna Zenyuk, Andrea Zitolo, Frederic Jaouen

\section{To cite this version:}

Jingkun Li, Sebastian Brüller, Dinesh Sabarirajan, Nastaran Ranjbar-Sahraie, Moulay Tahar Sougrati, et al.. Designing the 3D Architecture of PGM-Free Cathodes for H 2 / Air Proton Exchange Membrane Fuel Cells. ACS Applied Energy Materials, 2019, 2 (10), pp.7211-7222. 10.1021/acsaem.9b01181. hal-02352319

\section{HAL Id: hal-02352319 https://hal.science/hal-02352319}

Submitted on 16 Nov 2020

HAL is a multi-disciplinary open access archive for the deposit and dissemination of scientific research documents, whether they are published or not. The documents may come from teaching and research institutions in France or abroad, or from public or private research centers.
L'archive ouverte pluridisciplinaire $\mathbf{H A L}$, est destinée au dépôt et à la diffusion de documents scientifiques de niveau recherche, publiés ou non, émanant des établissements d'enseignement et de recherche français ou étrangers, des laboratoires publics ou privés. 


\section{Designing the 3D architecture of PGM-free cathodes for $\mathrm{H}_{2}$ /air proton exchange membrane fuel cells}

Jingkun Li ${ }^{l}$, Sebastian Brüller ${ }^{1}$, Dinesh C. Sabarirajan ${ }^{2}$, Nastaran Ranjbar-Sahraie $^{l}$, Moulay

Tahar Sougrati ${ }^{1}$, Sara Cavaliere ${ }^{1}$, Deborah Jones ${ }^{1}$, Iryna V. Zenyuk ${ }^{3}$, Andrea Zitolo ${ }^{4}$, and Frédéric Jaouen $^{1} *$

1 Institut Charles Gerhardt Montpellier, UMR 5253, CNRS, Université Montpellier, ENSCM, Place Eugène Bataillon, 34095 Montpellier cedex 5, France

2 Department of Mechanical Engineering, Tufts University, 200 Boston Avenue 2600, Medford, MA, 02155

3 Department of Chemical and Biomolecular Engineering, National Fuel Cell Research Center, University of California Irvine, Irvine, 92697, United States

4 Synchrotron SOLEIL, L’orme des Merisiers, BP 48 Saint Aubin, 91192 Gif-sur-Yvette, France

* J. L.: jingkun.li@umontpellier.fr; S.C.: sara.cavaliere@umontpellier.fr; F.J.:

frederic.jaouen@umontpellier.fr 


\section{ABSTRACT}

Metal-Nitrogen-Carbon catalysts have emerged as the most promising platinum group metal-free catalysts toward oxygen reduction reaction for proton exchange membrane fuel cell (PEMFC) applications. However, their large-scale implementation in $\mathrm{H}_{2}$ /air PEMFCs is still hindered by the low density of active sites in such materials, implying the need for thick active layers with inferior mass-transport properties. In this work, the co-electrospinning of nano-ZIF-8 (a zeolitic imidazolate framework) and polyacrylonitrile results in anisotropic and microporous FeNC fibers, offering an effective approach towards active layers with hierarchical micro-, meso- and macroporosity. X-ray computed tomography performed on the cathode ex situ reveals enhanced macroporosity of fibrous FeNC layers compared to a non-fibrous one derived from nano-ZIF-8. Applied in operando in a PEMFC, X-ray tomography showed abundant water-free macroporous voids in the fibrous FeNC layer, beneficial for the transport of reactants and products toward and away from the active sites. The combination of the Fe precursor in the electrospun solution and the high voltage applied during electrospinning is however also shown to enhance the formation of metallic Fe particles after pyrolysis, which is detrimental to the density of atomicallydispersed $\mathrm{FeN}_{\mathrm{x}}$ active sites. FeNC fibrous morphology with higher density of $\mathrm{FeN}_{\mathrm{x}}$ active sites, obtained with a modified electrospinning process or other techniques, holds therefore great potential to replace $\mathrm{Pt} / \mathrm{C}$ with $\mathrm{MNC}$ cathodes in $\mathrm{H}_{2}$ /air PEMFCs.

KEYWORDS: proton exchange membrane fuel cell, oxygen reduction reaction, iron-nitrogencarbon catalyst, electrospinning, mass-transport 


\section{Introduction}

The proton exchange membrane fuel cell (PEMFC) is a key technology to provide clean and sustainable energy conversion with potential applications in portable electronics, electric vehicles, residential power generation, etc. However, a significant amount of Pt-based catalysts is required at the cathode side to accelerate the sluggish kinetics of the oxygen reduction reaction (ORR), a long-standing impediment for their large-scale implementation. Thus, in the past decades, extensive efforts have been devoted to reducing or eliminating the use of precious metals at the cathode side. ${ }^{1-5}$ Metal-nitrogen-carbon (MNC) materials with atomically dispersed $\mathrm{MN}_{\mathrm{x}}$ active sites are the most promising class of platinum group metal (PGM)-free catalysts. ${ }^{6-9}$

Since the first report on the catalytic activity toward ORR of N-ligated cobalt in $1964,{ }^{10}$ FeNC catalysts prepared with optimized synthesis (leading to mostly or only $\mathrm{FeN}_{\mathrm{x}}$ sites via the pyrolysis of appropriate $\mathrm{Fe}, \mathrm{N}$, and $\mathrm{C}$ precursors at $800-1100{ }^{\circ} \mathrm{C}$ ) have exhibited high ORR activity in acidic media, with half-wave potential measured by a rotating disk electrode (RDE) approaching that of Pt/C. ${ }^{11-14}$ Such FeNC materials based on $\mathrm{FeN}_{\mathrm{x}}$ active sites have also been shown recently to reach the durability target set by the United States Department of Energy (activity loss $<25 \%$ after 30,000 load cycles at $80^{\circ} \mathrm{C}$ in $\mathrm{N}_{2}$-saturated acid medium). ${ }^{15}$ These recent advancements bring us closer to empowering PGM-free cathodes in PEMFCs.

However, the viability of FeNC catalysts in $\mathrm{H}_{2}$ /air PEMFCs is limited by their inferior masstransport properties due to the high catalyst loading $\left(\sim 4 \mathrm{mg} \cdot \mathrm{cm}^{-2}\right.$, resulting in $70-100 \mu \mathrm{m}$ thick layer) that is required to reach sufficient electrode activity at elevated potentials. ${ }^{14,16,17}$ The lower activity per mass of catalyst, or per electrode volume, for FeNC catalysts vs. $\mathrm{Pt} / \mathrm{C}$ is a direct consequence of the lower density of $\mathrm{FeN}_{\mathrm{x}}$ sites (only 1-4 wt.\% Fe, even in state-of-the-art 
FeNC catalysts). ${ }^{11,14,18}$ Micropores (defined as pores with diameter $<2 \mathrm{~nm}$ ) were identified as hosts of $\mathrm{FeN}_{\mathrm{x}}$ sites formed during pyrolysis, ${ }^{17,19}$ and the use of microporous Zn-based metal organic frameworks (in particular, ZIF-8) as a dual carbon and nitrogen source was subsequently shown to result in FeNC materials with superior microporosity. ${ }^{11,13,17,20-23}$ This leads to enhanced active site densities and ORR activities in FeNC catalysts. However, the drawback is that the predominance of narrow pores (micropores and small mesopores, with mesopores defined as pores with diameter between 2 and $50 \mathrm{~nm}$ ) in catalysts derived from ZIF-8 or other metal-organic frameworks results in limited access of reactants to, and products away from, the active sites. $^{24}$ The issue of slow mass-transport in microporous FeNC materials is further exacerbated by the elongated travel distances of reactants caused by the current need for thick cathode layers, as explained earlier. In addition, water management has been shown to strongly depend on local wettability, electrode and interfacial morphologies. ${ }^{25,}{ }^{26}$ Moreover, the stability of microporous FeNC catalysts in operating PEMFC is a long-standing challenge that can be assigned, in whole or in part, to water-flooding issues of cathode layers prepared from microporous FeNC powders and/or high concentration in micropores of $\mathrm{H}_{2} \mathrm{O}_{2}$ by-products formed during ORR. ${ }^{27-30}$ Thus, advancements in both power performance and stability call for a rational control of the electrode structure with proper micro- and macroporosity (macropores are defined as pores with diameter $>50 \mathrm{~nm})$.

Electrospinning has been demonstrated as an effective approach to introduce macroporous voids, leading to enhanced mass-transport properties and/or stability of FeNC cathode layers in PEMFC. ${ }^{31-35}$ The carbon nanofiber (CNF) morphology obtained with this process is the key for securing macroporosity in catalytic layers. In particular, co-electrospinning ZIF-8 together with a polymer can result in CNFs with abundant micropores. ${ }^{32,33}$ The micropores hold great potential 
to achieve a high active-site density in FeNC, while the fibrous geometry is beneficial for enhanced mass-transport properties in catalytic layers. In addition, the macroporous voids between CNFs can also act as water drains during PEMFC operation, mitigating flooding issues in micro- and mesopores. Despite promising results, two critical aspects related to the use of electrospinning have been under-investigated in previous studies on the co-electrospinning of ZIF-8 and a polymer carrier as a strategy for preparing FeNC catalysts. The first critical aspect concerns the Fe speciation after pyrolysis, and the lack of a clear view whether the same or different Fe speciation was obtained compared to the well-established synthesis approaches involving ZIF-8 powder. ${ }^{32}$ The second critical aspect relates to tuning the crystal size of ZIF-8 smaller than the polymer fibre diameter for i) improved $\mathrm{O}_{2}$ accessibility of active sites in the ORR-active domains resulting from pyrolyzed Fe-doped ZIF-8, and ii) sufficient mechanical stability of FeNC microporous fibres derived from ZIF-8/polymer fibre composites. Mechanical stability of the fibres is, in turn, key for longstanding improved mass-transport properties inside electrodes. The tuning of ZIF-8 crystal size has been shown to be critical for the ORR activity of ZIF-8 derived FeNC powder catalysts, ${ }^{36,}{ }^{37}$ but not applied yet in the context of FeNC layer preparation via electrospinning.

Herein, we introduce a controlled three-dimensional (3D) architecture of FeNC catalysts engineered via the electrospinning of Fe-doped nano-ZIF-8 (ZIF-8(Fe)) with a polymer. As a reference material, ZIF-8(Fe) was pyrolyzed as such, without resorting to electrospinning. The presence of iron oxide nanoclusters in $\mathrm{ZIF}-8(\mathrm{Fe})$ and their dispersion into atomically-dispersed $\mathrm{FeN}_{\mathrm{x}}$ sites during pyrolysis was demonstrated. However, ZIF-8 $(\mathrm{Fe})$ electrospun with a carrier polymer (PAN, polyacrylonitrile) resulted, during pyrolysis, in the transformation of a small fraction of $\mathrm{Fe}$ into $\mathrm{FeN}_{\mathrm{x}}$ sites and a large fraction into metallic $\mathrm{Fe}$ and iron-carbide. Despite a 
lower density of $\mathrm{FeN}_{\mathrm{x}}$ sites, nano-ZIF-8(Fe) electrospun with PAN resulted in higher ORR activity and enhanced mass-transport properties in a $\mathrm{H}_{2}$ /air PEMFC compared to pyrolyzed nanoZIF-8(Fe). This is attributed to the FeNC fibrous morphology obtained with electrospinning, leading to a higher content of macropores in the cathode layer. Operando X-ray tomography also revealed the role of macroporous voids in alleviating cathode flooding during PEMFC operation. This work provides novel insights on the desired 3D architecture for high performance FeNC electrodes in $\mathrm{H}_{2}$ /air PEMFCs, but also identifies unexpected challenges in the selected processes to maintain atomic dispersion of the metal as $\mathrm{MN}_{\mathrm{x}}$ sites after pyrolysis.

\section{Results and Discussion}

\subsection{Structure and Fe coordination in Fe-doped nano-ZIF-8}

An optimized amount of Fe was introduced in nano-ZIF-8 (ZIF-8(Fe)) during ZIF-8 synthesis by mixing iron(II) and zinc(II) salt solution with 2-methylimidazole solution in methanol at room temperature (Figure 1a, details are described in Methods). An organic base (butylamine) was added to accelerate the growth of ZIF-8, resulting in nanosized rhombic dodecahedral ZIF-8(Fe) crystals ( $60 \mathrm{~nm}$, Figure 1b). The addition of Fe did not affect the crystalline structure of ZIF-8 as confirmed by X-ray diffraction (XRD) (Figure 2a). Other groups suggested that such one-pot synthesis of ZIF-8(Fe) leads to the partial replacement of $\mathrm{Zn}(\mathrm{II})$ by $\mathrm{Fe}(\mathrm{II})$ in $\mathrm{ZIF}-8$, incorporating $\mathrm{Fe}$ as tetrahedral $\mathrm{FeN}_{4}$ coordination truly participating in the crystal structure of the metalorganic framework. ${ }^{13}$ However, no evidence supports this hypothesis in the present study, since the XRD (Figure 2a), Fourier-transform infrared (FT-IR) and FT-far-IR spectra (Figure S1) of ZIF-8 and ZIF-8(Fe) exhibit identical characteristic peaks. Specifically, one would expect different vibration frequencies in FT-far-IR for $\mathrm{ZnN}_{4}$ and $\mathrm{FeN}_{4}$ tetrahedral coordination. 
According to $\mathrm{N}_{2}$ sorption results (Figure $2 \mathbf{b}$ and Table S1), Fe-doping reduced the BET surface area of ZIF-8 from 1638 to $758 \mathrm{~m}^{2} \cdot \mathrm{g}^{-1}$. This strongly suggests that iron species were either adsorbed on the surface of ZIF-8 and/or encapsulated in ZIF-8 cavities, during the synthesis of ZIF-8(Fe). In contrast, partial replacement of $\mathrm{Zn}(\mathrm{II})$ by $\mathrm{Fe}(\mathrm{II})$ at the nodes of the otherwise unmodified ZIF-8 crystal structure would not affect the surface area significantly. We also performed ${ }^{57} \mathrm{Fe}$ Mössbauer spectroscopy to investigate the electronic environment of $\mathrm{Fe}$ in ZIF8(Fe). Unfortunately, it was Mössbauer-silent, possibly due to (i) high Zn content absorbing most of the $\gamma$-rays, and (ii) high recoil of Fe during $\gamma$-ray absorption event (weak Fe binding to the ZIF-8 solid) leading to low Lamb-Mössbauer factors. We then resorted to X-ray absorption spectroscopy (XAS). The Fourier transform of the Fe K-edge extended X-ray absorption fine structure (FT-EXAFS) spectrum of ZIF-8(Fe) (Figure 2c) reveals two major peaks at 1.5 and 2.7 $\AA$. Their positions match that of the Fe-O first-shell and Fe-Fe second-shell contributions of a reference $\mathrm{Fe}_{2} \mathrm{O}_{3}$ FT-EXAFS spectrum, respectively. The lower relative intensity of the $\mathrm{Fe}-\mathrm{Fe}$ scattering peak in ZIF-8(Fe) can be explained by (sub)-nanostructured clusters, and/or defects of iron oxide in ZIF-8(Fe). Based on FT-far-IR, BET surface area and EXAFS results, we can thus infer that $\mathrm{Fe}$ atoms in $\mathrm{ZIF}-8(\mathrm{Fe})$ predominantly exist as (sub)-nano-sized iron oxide, either encapsulated in ZIF-8 cavities or adsorbed on the surface of ZIF-8 crystals. However, the coordination of a small fraction of $\mathrm{Fe}$ as tetrahedral $\mathrm{Fe}-\mathrm{N}_{4}$ sites replacing $\mathrm{Zn}$ nodes in the crystal structure of ZIF-8 cannot be excluded. As will be demonstrated later, (sub)-nano-sized iron oxide clusters in ZIF-8 $(\mathrm{Fe})$ leads to atomically-dispersed $\mathrm{FeN}_{\mathrm{x}}$ sites after pyrolysis, in the conventional approach of preparing FeNC catalysts via the pyrolysis of ZIF-8(Fe) powder (no electrospinning). 


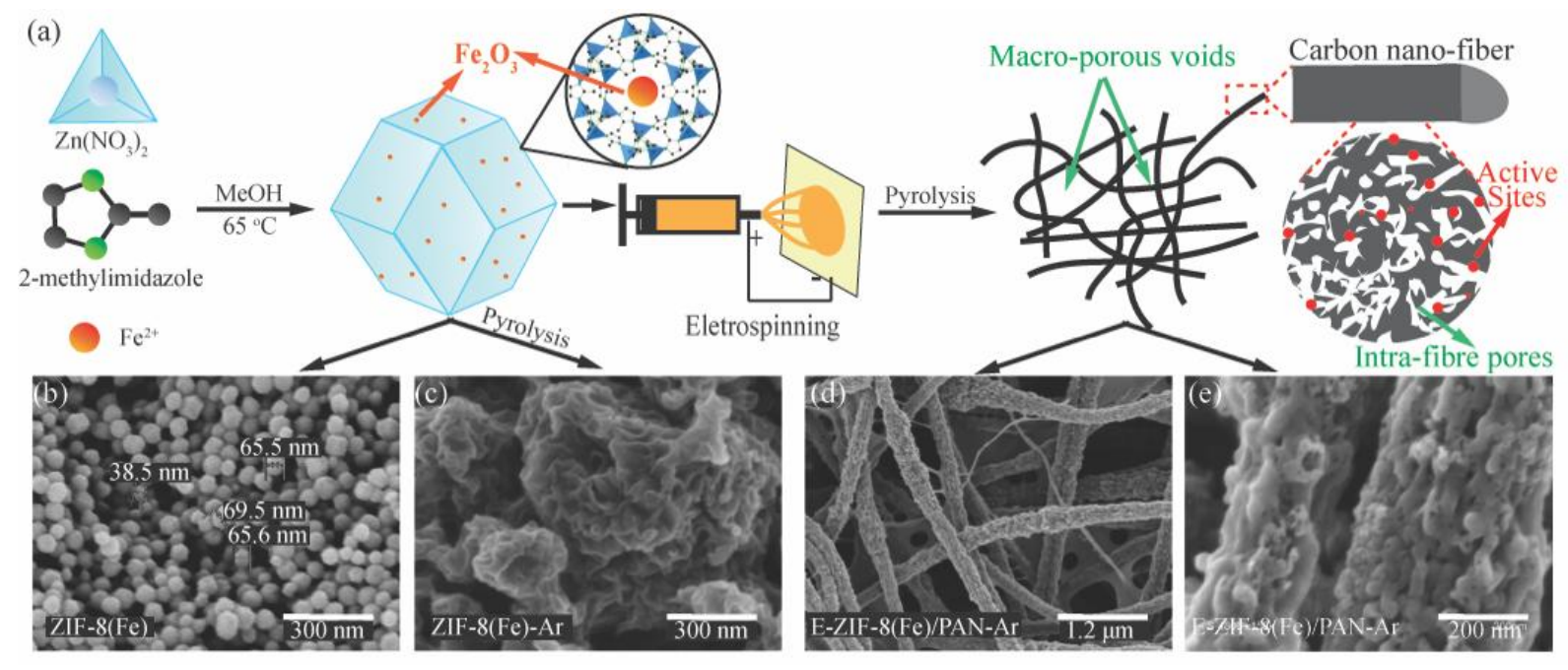

Figure 1. Synthesis and morphology. (a) Schematic illustration of the synthetic approach of EZIF-8(Fe)/PAN-Ar. SEM images of ZIF-8(Fe) (b), ZIF-8(Fe)-Ar (c) and E-ZIF-8(Fe)/PAN-Ar before grinding (d-e). 

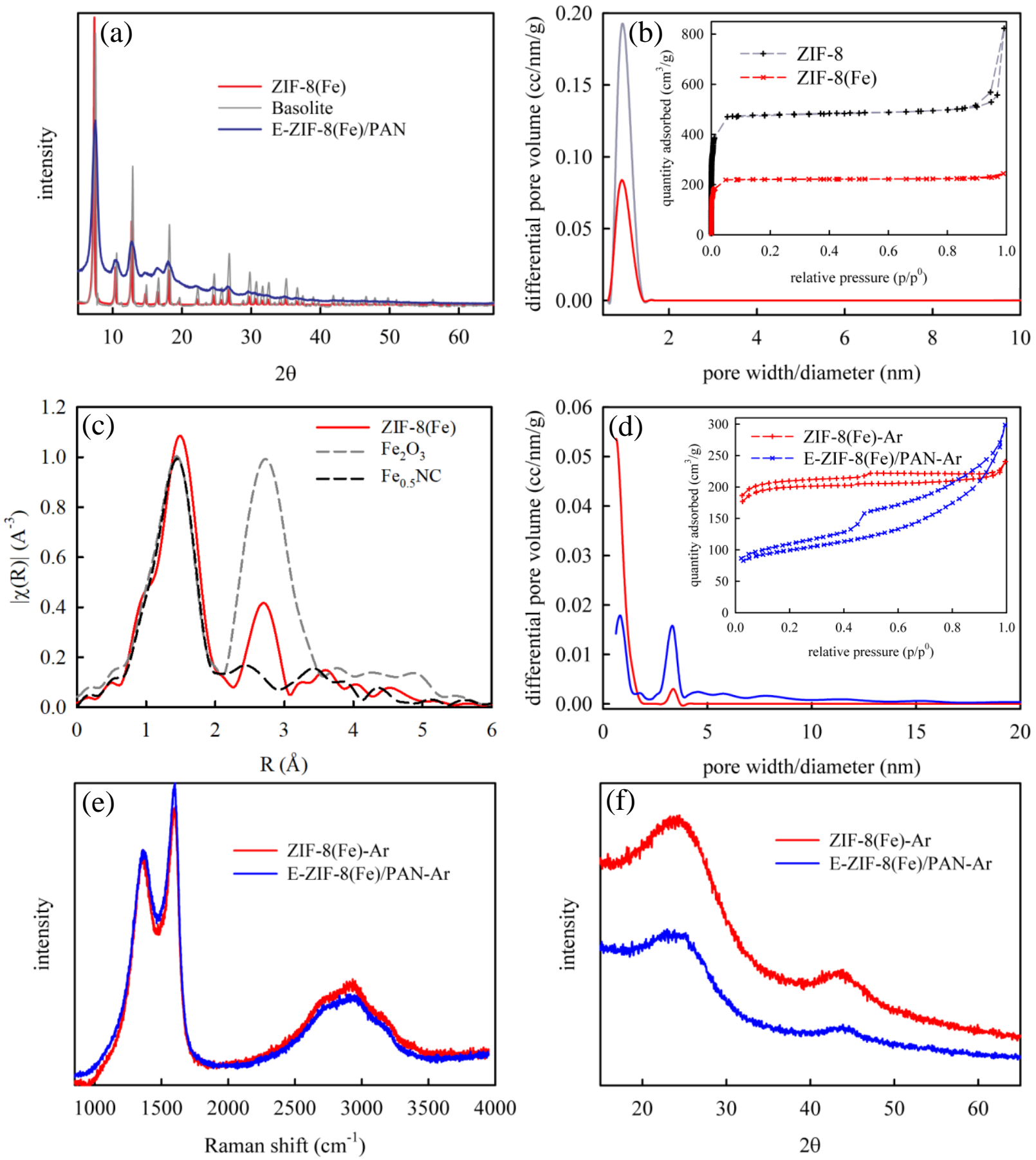

Figure 2. Physical characterizations. (a) XRD patterns of ZIF-8(Fe), E-ZIF-8(Fe)/PAN and commercial Basolite ${ }^{\circledR}$ Z1200. (b) Pore size distributions and $\mathrm{N}_{2}$ adsorption/desorption isotherms (inset) of ZIF-8(Fe) and ZIF-8 (identically synthesized but without Fe-doping). (c) Fe K-edge 
FT-EXAFS spectra of ZIF-8(Fe), $\mathrm{Fe}_{0.5} \mathrm{NC}$ (a reference FeNC catalyst prepared from ZIF-8 and containing exclusively atomically dispersed $\mathrm{FeN}_{\mathrm{x}}$ sites, ref. 11), and $\mathrm{Fe}_{2} \mathrm{O}_{3}$ (no phase-shift correction applied). (d) Pore size distributions and $\mathrm{N}_{2}$ adsorption/desorption isotherms (inset) of ZIF-8(Fe)-Ar and E-ZIF-8(Fe)/PAN-Ar. (e) Raman spectra of ZIF-8(Fe)-Ar and E-ZIF8(Fe)/PAN-Ar. (f) XRD patterns of ZIF-8(Fe)-Ar and E-ZIF-8(Fe)/PAN-Ar.

\subsection{Morphology and pore structure of FeNC catalysts}

Then, ZIF-8(Fe) was electrospun together with PAN (denoted as E-ZIF-8(Fe)/PAN hereafter), followed by a heat-treatment at $1050{ }^{\circ} \mathrm{C}$ under $\mathrm{Ar}$ (denoted as E-ZIF-8(Fe)/PAN-Ar hereafter) (Figure 1a). It should be noted here that, for most of the characterizations, the above fibrous web was manually grinded for 5 minutes, and E-ZIF-8(Fe)/PAN-Ar represents the grinded fibers, unless otherwise stated. The XRD patterns of E-ZIF-8(Fe)/PAN fibers exhibit the same characteristic peaks as ZIF-8 (Figure 2a), confirming that the crystalline structure of ZIF-8(Fe) was retained after the electrospinning process. However, ZIF-8(Fe) crystals were invisible in the scanning electron microscopy (SEM) images of E-ZIF-8(Fe)/PAN fibers (Figure S2), due probably to the homogeneous mixing of PAN and ZIF-8(Fe). As a control sample, ZIF-8(Fe) powder was heat-treated under the same conditions (denoted as ZIF-8(Fe)-Ar hereafter), i.e. this sample was not mixed with PAN and not subjected to electrospinning. In contrast to the densely packed carbon powder morphology of ZIF-8(Fe)-Ar (Figure 1c), E-ZIF-8(Fe)/PAN-Ar exhibits a 3D CNF web morphology with numerous macropores (Figure 1d). The network of carbon fibers with an evenly distributed diameter around $400 \mathrm{~nm}$ is inherited from E-ZIF-8(Fe)/PAN (Figure S2), while the porous structure inside the CNF observed in the SEM close-look image (Figure 1e) is derived from ZIF-8(Fe) nanocrystals homogeneously mixed with PAN. The synthesis of nano-ZIF-8(Fe) with crystal size significantly smaller than the diameter of PAN- 
based fibers plays a critical role in allowing the formation of microporous CNFs during pyrolysis. Due to the nanostructuration of $\mathrm{ZIF}-8(\mathrm{Fe})$, the ratio of $\mathrm{ZIF}-8(\mathrm{Fe}) / \mathrm{PAN}$ used during electrospinning could be increased to 60/40 (by weight) while maintaining structural integrity of the fibers after pyrolysis. This is a significant achievement compared to previous studies, where ZIF-8 crystals with larger size lead to brittle CNFs and/or forced the use of lower ZIF-8/PAN ratio, thereby reducing the number of active sites in pyrolyzed catalysts. ${ }^{32}$

In addition to evidence provided by SEM, the presence of abundant macropores in E-ZIF8(Fe)/PAN-Ar was further confirmed with mercury intrusion porosimetry (Figure S3), with a

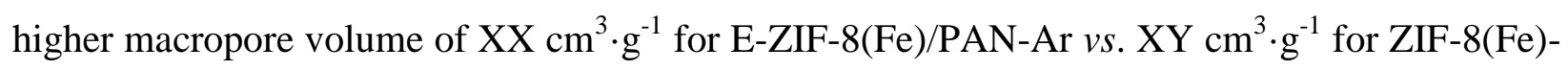
$\operatorname{Ar}$ (Table S1). Moreover, micro- and mesopores in both samples were investigated with $\mathrm{N}_{2}$ adsorption. The sorption isotherms of ZIF-8(Fe)-Ar and E-ZIF-8(Fe)/PAN-Ar are typical for pure microporous and micro-meso-porous materials, respectively (Figure 2d). The micropore volume in $\mathrm{ZIF}-8(\mathrm{Fe})-\mathrm{Ar}$ is $c a$. twice larger than in E-ZIF-8(Fe)/PAN-Ar, as assessed from the sudden rise in $\mathrm{N}_{2}$ volume adsorbed at low $\mathrm{P} / \mathrm{P}_{0}$, and thus twice larger BET area (mostly coming from micropores) (Table S1, 605 and $322 \mathrm{~m}^{2} \cdot \mathrm{g}^{-1}$ ). This can be interpreted by a dilution effect, only the carbon domains derived from ZIF-8(Fe) contributing to the micropore volume in E-ZIF8(Fe)/PAN-Ar, while those derived from PAN are known to form non-porous CNFs with BET area $<20 \mathrm{~m}^{2} \cdot \mathrm{g}^{-1} \cdot{ }^{38}$ The $\mathrm{N}_{2}$ sorption isotherm of E-ZIF-8(Fe)/PAN-Ar is also distinct from that of ZIF-8(Fe)-Ar due to the tilted shape and higher hysteresis, assigned to large and small mesopores, respectively. The higher amount of such pores may be assigned to the fibrous morphology and surface roughness of fibres in E-ZIF-8(Fe)/PAN-Ar (Figure 1d-e). The average structure and graphitization of the carbon phases present in both materials was also investigated with Raman spectroscopy. E-ZIF-8(Fe)/PAN-Ar exhibits a slightly higher peak intensity of the G band (1590 
$\mathrm{cm}^{-1}$ ) than that of ZIF-8(Fe)-Ar (Figure 2e), indicating a somewhat higher average degree of graphitization, that can be assigned to the slightly more graphitic carbon phase derived from PAN compared to that derived from ZIF-8(Fe). ${ }^{39}$ In summary, E-ZIF-8(Fe)/PAN-Ar has a hierarchical micro-, meso- and macroporous structure, expected to benefit the power performance in $\mathrm{H}_{2} /$ air PEMFC operation. ${ }^{32}$

\subsection{Iron speciation in FeNC catalysts}

To identify Fe species in the materials, XRD was performed first as a routine technique suited to identify crystallographically ordered Fe particles. However, only two broad peaks attributed to the (002) and (101) facets of graphite were observed from the XRD patterns of ZIF-8(Fe)-Ar and E-ZIF-8(Fe)/PAN-Ar (Figure 2f). This suggests either that there is no or minimal amount of metallic Fe particles in those two samples, or the metallic particles are hardly ordered and/or nanometric. Thus, we resorted to XAS and ${ }^{57} \mathrm{Fe}$ Mössbauer spectroscopy to more accurately investigate the iron species present in ZIF-8(Fe)-Ar and E-ZIF-8(Fe)/PAN-Ar.

The Fe K-edge X-ray absorption near edge spectroscopy (XANES) spectrum of ZIF-8(Fe)-Ar overlaps with that of $\mathrm{Fe}_{0.5} \mathrm{NC}$ (Figure 3a). The latter is a reference $\mathrm{FeNC}$ catalyst from our laboratory, prepared by mixing ZIF-8 and ferrous acetate and known to exclusively contain atomically-dispersed $\mathrm{FeN}_{\mathrm{x}}$ sites. ${ }^{11}$ The FT-EXAFS spectrum of ZIF-8(Fe)-Ar is also similar to that of $\mathrm{Fe}_{0.5} \mathrm{NC}$, exhibiting a single peak at $\sim 1.5 \AA$ arising from Fe-N first-shell scattering (and Fe-O, when $\mathrm{O}_{2}$ is adsorbed on $\mathrm{FeN}_{\mathrm{x}}$ sites) (Figure 3b). XAS results thus indicate that iron in $\mathrm{ZIF}-8(\mathrm{Fe})-\mathrm{Ar}$ is in the same coordination as in $\mathrm{Fe}_{0.5} \mathrm{NC}$, i.e. overwhelmingly present as atomically dispersed $\mathrm{FeN}_{\mathrm{x}}$ sites. ${ }^{11,17,18,40}$ These results agree well with the ${ }^{57} \mathrm{Fe}$ Mössbauer spectrum of ZIF-8(Fe)-Ar (Figure 3c and Table 1), which was fitted with two doublets D1 and 
D2, representing $97 \%$ of the signal and assigned to different $\mathrm{FeN}_{\mathrm{x}}$ species, ${ }^{11,17,18,40-42}$, and a singlet assigned to $\gamma$-Fe representing only $3 \%$ of the resonant area. The XAS and ${ }^{57} \mathrm{Fe}$ Mössbauer characterizations thus unambiguously demonstrate that the iron oxide (sub)nano-particles present in $\mathrm{ZIF}-8(\mathrm{Fe})$ redispersed almost completely into single-atom $\mathrm{FeN}_{\mathrm{x}}$ sites during pyrolysis. Complete atomic dispersion of $\mathrm{Fe}$ in a precursor is thus not a necessary condition to obtain atomic $\mathrm{FeN}_{\mathrm{x}}$ sites after pyrolysis, in line with recent studies on redispersion of metal nanoparticles into single-atom $\mathrm{MN}_{\mathrm{x}}$ moieties upon heating. ${ }^{43,44}$ 

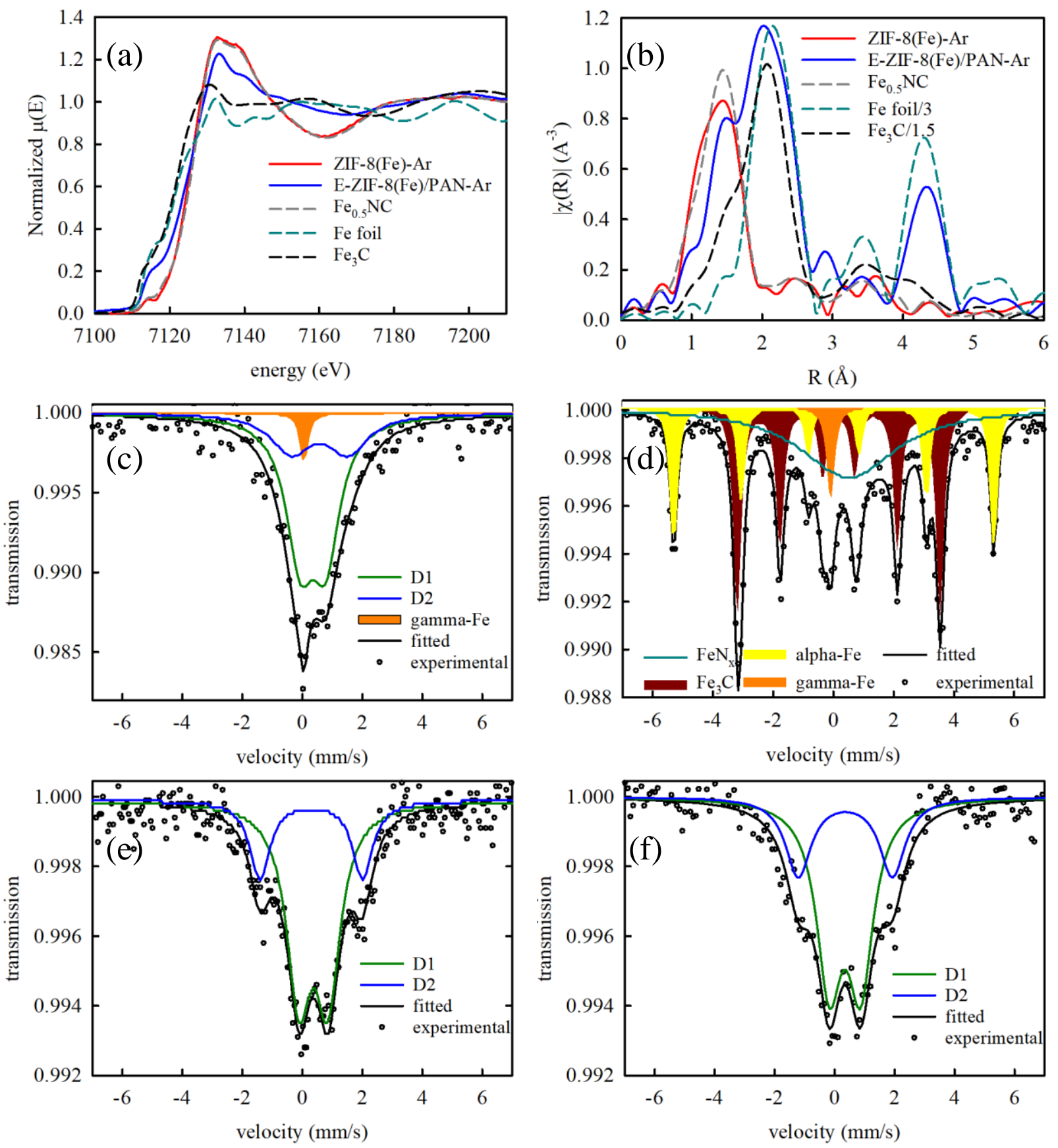

Figure 3. Iron speciation. (a) Fe K-edge XANES spectra of ZIF-8(Fe)-Ar and E-ZIF8(Fe)/PAN-Ar, and (b) their corresponding FT-EXAFS spectra (no phase-shift correction applied). The spectra of $\mathrm{Fe}_{0.5} \mathrm{NC}$ (a FeNC catalyst with exclusively atomically dispersed $\mathrm{FeN}_{\mathrm{x}}$ sites, Ref. 11), $\mathrm{Fe}$ foil and $\mathrm{Fe}_{3} \mathrm{C}$ are presented as references for pure compounds. ${ }^{57} \mathrm{Fe}$ Mössbauer 
spectroscopy of (c) ZIF-8(Fe)-Ar, (d) E-ZIF-8(Fe)/PAN-Ar, (e) ZIF-8(Fe)/PAN-Ar and (f) ZIF8(Fe)-stabilized-Ar.

Table 1. Mössbauer parameters derived from the fittings: relative area (RA), isomer shift (IS), quadrupole splitting (QS), line width (LW) and magnetic field (H) of each component.

\begin{tabular}{|c|c|c|c|c|c|c|c|}
\hline Sample & Comp. & $\begin{array}{l}\text { RA } \\
\%\end{array}$ & $\begin{array}{c}\mathrm{IS} \\
\mathrm{mm} \cdot \mathrm{s}^{-1}\end{array}$ & $\begin{array}{c}\mathrm{QS} \\
\mathrm{mm} \cdot \mathrm{s}^{-1}\end{array}$ & $\begin{array}{c}\mathrm{LW} \\
\mathrm{mm} \cdot \mathrm{s}^{-1}\end{array}$ & $\begin{array}{c}\mathrm{H} \\
\text { Tesla }\end{array}$ & Assignment \\
\hline \multirow{3}{*}{ ZIF-8(Fe)-Ar } & Singlet & 3 & 0.05 & - & 0.30 & - & $\gamma-\mathrm{Fe}$ \\
\hline & Doublet 1 & 69 & 0.35 & 0.85 & 1.14 & - & $\mathrm{FeN}_{\mathrm{x}}$ \\
\hline & Doublet $2^{\mathrm{a}}$ & 28 & 0.57 & 1.91 & 1.58 & . & $\mathrm{FeN}_{\mathrm{x}}$ \\
\hline \multirow{4}{*}{$\begin{array}{c}\text { E-ZIF- } 8(\mathrm{Fe}) / \mathrm{PAN}- \\
\mathrm{Ar}\end{array}$} & Sextet 1 & 36 & 0.18 & - & 0.31 & 20.9 & $\mathrm{Fe}_{3} \mathrm{C}$ \\
\hline & Sextet 2 & 20 & 0.01 & - & 0.27 & 33.0 & $\alpha-\mathrm{Fe}$ \\
\hline & Singlet 1 & 4 & -0.09 & - & 0.33 & - & $\gamma-\mathrm{Fe}$ \\
\hline & Singlet 2 & 40 & 0.50 & - & 3.92 & - & $\mathrm{FeN}_{\mathrm{x}}$ \\
\hline \multirow{2}{*}{ ZIF-8(Fe)/PAN-Ar } & Doublet 1 & 74 & 0.37 & 0.97 & 1.00 & - & $\mathrm{FeN}_{\mathrm{x}}$ \\
\hline & Doublet $2^{\mathrm{a}}$ & 26 & 0.30 & 3.43 & 0.83 & - & $\mathrm{FeN}_{\mathrm{x}}$ \\
\hline \multirow{2}{*}{$\begin{array}{c}\text { ZIF-8(Fe)- } \\
\text { stabilized-Ar }\end{array}$} & Doublet 1 & 69 & 0.34 & 1.05 & 1.02 & - & $\mathrm{FeN}_{\mathrm{x}}$ \\
\hline & Doublet $2^{\mathrm{a}}$ & 31 & 0.36 & 3.14 & 1.03 & - & $\mathrm{FeN}_{\mathrm{x}}$ \\
\hline
\end{tabular}

${ }^{a}$ There are some differences in the Mössbauer parameters of D2 compared to those observed in $\mathrm{Fe}_{0.5} \mathrm{NC}$ (see Supplementary text).

The Fe speciation in E-ZIF-8(Fe)/PAN-Ar was then investigated. This material exhibits XANES (Figure 3a), FT-EXAFS (Figure 3b) and ${ }^{57} \mathrm{Fe}$ Mössbauer (Figure 3d) spectra that are drastically different from those of ZIF-8(Fe)-Ar. The ${ }^{57} \mathrm{Fe}$ Mössbauer spectrum of E-ZIF-8(Fe)/PAN-Ar (Figure 3d and Table 1) was fitted with four components, namely sextet 1 assigned to $\mathrm{Fe}_{3} \mathrm{C}$ (36\%), sextet 2 assigned to $\alpha$-Fe (20\%), singlet 1 assigned to $\gamma$-Fe (4\%) and a broad singlet 2 (40\%). The latter can, in general, be assigned to highly disordered $\mathrm{FeN}_{\mathrm{x}}$ sites or magnetically relaxing nanoparticles. It should be noted that neither doublet D1 nor D2, widely observed in FeNC catalysts, ${ }^{11,17,18,40}$ is present in E-ZIF-8(Fe)/PAN-Ar spectrum. No sextet that can be assigned to Fe-oxides was detected by Mössbauer spectroscopy. The Fe K-edge FT-EXAFS spectrum of E-ZIF-8(Fe)/PAN-Ar exhibits three major peaks at $\sim 1.5, \sim 2.1$ and $\sim 4.3 \AA$ (Figure 
3b). The second and third peak at $\sim 2.1$ and $\sim 4.3 \AA$ in the FT-EXAFS spectrum of E-ZIF8(Fe)/PAN-Ar arises from Fe-Fe scattering contributed by the $\mathrm{Fe}_{3} \mathrm{C}, \alpha$ - and $\gamma$-Fe phases, while the first peak can be attributed to $\mathrm{Fe}-\mathrm{N} / \mathrm{O}$ (from $\mathrm{FeN}_{\mathrm{x}}$ moieties) and/or $\mathrm{Fe}-\mathrm{C}$ (from $\mathrm{Fe}_{3} \mathrm{C}$ ) scattering paths (Figure 3b). In contrast to the relatively low peak intensity at $\sim 1.5 \AA$ vs. that at $2.1 \AA$ in the FT-EXAFS of $\mathrm{Fe}_{3} \mathrm{C}$, the strong intensity of the peak at $\sim 1.5 \AA$ ss. that at $2.1 \AA$ of EZIF-8(Fe)/PAN-Ar can only be explained if all or most of the signal from singlet 2 is assigned to $\mathrm{FeN}_{\mathrm{x}}$ sites. The singlet 2 was identified in other FeNC materials comprising numerous Fe species, and was assigned to $\mathrm{FeN}_{\mathrm{x}}$ moieties. ${ }^{45,}{ }^{46}$ Such moieties may, in an environment rich in $\mathrm{Fe}$ metallic particles, loose their well-defined doublet spectral signature. In summary, E-ZIF8(Fe)/PAN-Ar comprises in the order of relative absorption area in the Mössbauer spectrum: $\mathrm{FeN}_{\mathrm{x}}$ moieties (40\% of the resonance signal in Mössbauer spectroscopy) $>\mathrm{Fe}_{3} \mathrm{C}(36 \%)>\alpha-\mathrm{Fe}$ $(20 \%)>\gamma-\mathrm{Fe}(4 \%)$

There are three possible reasons for the higher amount of inorganic Fe species in E-ZIF8(Fe)/PAN-Ar (60\% of the Mössbauer signal) relative to ZIF-8(Fe)-Ar (only $3 \%$ of the relative signal): 1) the presence of PAN during pyrolysis, 2) the mild thermal treatment at $240{ }^{\circ} \mathrm{C}$ in air performed before electrospinning to stabilize PAN, and 3) the electrospinning process itself. In order to identify which key factor resulted in the stronger formation of metallic particles in EZIF-8(Fe)/PAN-Ar, ${ }^{57} \mathrm{Fe}$ Mössbauer spectroscopy was performed on ZIF-8(Fe)/PAN-Ar (ZIF8(Fe) mixed with PAN exclusively via ball-milling and then pyrolyzed in Ar, to assess hypothesis 1) and ZIF-8(Fe)-stabilized-Ar (ZIF-8(Fe) subjected to a thermal treatment in air at $240{ }^{\circ} \mathrm{C}$ and then pyrolyzed in Ar, to assess hypothesis 2 ). The ${ }^{57} \mathrm{Fe}$ Mössbauer spectra of ZIF8(Fe)/PAN-Ar (Figure 3e) and ZIF-8(Fe)-stabilized-Ar (Figure 3f) could be fitted with D1 and D2 doublet components assigned to $\mathrm{FeN}_{\mathrm{x}}$ moieties, with relative areas similar to that of ZIF- 
8(Fe)-Ar. This indicates that neither the presence of PAN nor the stabilization at $240{ }^{\circ} \mathrm{C}$ in air induced the formation of inorganic species in E-ZIF-8(Fe)/PAN-Ar. It is understandable that thermal treatment in air at $240{ }^{\circ} \mathrm{C}$ did not alter the $\mathrm{Fe}$ speciation after pyrolysis since iron in ZIF$8(\mathrm{Fe})$ is already in the form of iron oxide (sub)-nanoclusters, and ZIF-8 is stable in air up to $300{ }^{\circ} \mathrm{C}^{47}$ Thus, we can infer that it is the high voltage and/or the strong surface tension during electrospinning (hypothesis No. 3 above) that resulted in the formation of metallic particles during pyrolysis. This might be explained by the aggregation of iron oxide clusters during the electrospinning, ${ }^{48}$ and these larger particles cannot be completely transformed to atomicallydispersed $\mathrm{FeN}_{\mathrm{x}}$ sites, but formed the metallic and metal carbide particles during pyrolysis.

Thus, E-ZIF-8(Fe)/PAN-Ar has a lower number of $\mathrm{FeN}_{\mathrm{x}}$ sites per gram of catalyst compared to ZIF-8(Fe)-Ar for two reasons: i) dilution of the ORR-active phase derived from ZIF-8(Fe) by the carbon phase derived from PAN, and ii) parallel formation of $\mathrm{FeN}_{\mathrm{x}}$ sites and $\mathrm{Fe}$ particles due to the electrospinning process. It is generally believed that $\mathrm{Fe}$ metallic species are less active per $\mathrm{Fe}$ atom (TOF-value) than $\mathrm{FeN}_{\mathrm{x}}$ moieties in acidic medium, ${ }^{7,18,40,49}$ and, recently demonstrated, also less stable. ${ }^{15}$ Thus, although electrospinning leads to a beneficial fibrous morphology of FeNC, we for the first time reveal it also has negative side effects on Fe speciation. In order to study the ambivalent effects of electrospinning on the Fe-speciation and morphology of FeNC, we measured the ORR activity and power performance of E-ZIF-8(Fe)/PAN-Ar and control samples with RDE and PEMFC.

\subsection{ORR performance in RDE and PEMFC}

The catalytic activities toward ORR of ZIF-8(Fe)-Ar and E-ZIF-8(Fe)/PAN-Ar were first investigated with RDE (Figure S4a-b). Both catalysts exhibit similar mass activities at $0.85 \mathrm{~V} v s$. 
RHE $\left(\sim 0.125 \mathrm{~A} \cdot \mathrm{g}^{-1}\right)$, and the same Tafel slope (TS) of $74 \mathrm{mV} \cdot \mathrm{dec}^{-1}$ in $0.1 \mathrm{M} \mathrm{HClO}_{4}$ (Figure S4b), close to values reported previously for FeNC catalysts. ${ }^{50}$ However, a much lower diffusion-limited current density was observed for ZIF-8(Fe)-Ar as compared with that of E-ZIF8(Fe)/PAN-Ar (Figure S4a). This can be explained by the lower electron transfer number of ZIF-8(Fe)-Ar ( 3.5) compared to that of E-ZIF-8(Fe)/PAN-Ar ( 4) calculated from a KouteckyLevich analysis at different rotation rates (Figure S5). Moreover, E-ZIF-8(Fe)/PAN-Ar exhibited a thicker envelope compared to $\mathrm{ZIF}-8(\mathrm{Fe})-\mathrm{Ar}$ as observed from cyclic voltammetry (CV) measured in $\mathrm{N}_{2}$-saturated electrolyte (Figure $\mathbf{S 4 c}$ ), indicating a higher electrochemical surface area (carbon surface). The lower BET area but higher electrochemical surface area observed for E-ZIF-8(Fe)/PAN-Ar suggests that the pores in this material are more accessible to the electrolyte than the pores in ZIF-8(Fe)-Ar. Penetration of liquid electrolyte into micropores can be influenced by many factors, e.g. the overall pore size distribution (amount of large meso/macropores and connectivity between micro and large meso/macropores), hydrophilic or hydrophobic character, pore geometries, etc. Thus, the higher accessibility of micropores in E$\mathrm{ZIF}-8(\mathrm{Fe}) / \mathrm{PAN}-\mathrm{Ar}$ is attributed to the higher amount of meso- and macropores in between the fibers of E-ZIF-8(Fe)/PAN-Ar compared to ZIF-8(Fe)-Ar (Figure2d, S3 and Table S1), which is the key for the better ORR activity of E-ZIF-8(Fe)/PAN-Ar.

The catalytic activities and initial power performance of ZIF-8(Fe)-Ar and E-ZIF-8(Fe)/PAN-Ar were then evaluated with a single-cell PEMFC with a cathode loading of $4 \mathrm{mg} \cdot \mathrm{cm}^{-2}$ under both oxygen (Figure 4a-b) and air (Figure 4c-d) feed at the cathode. It should be noted here that the self-standing fibrous web of E-ZIF-8(Fe)/PAN-Ar was grinded and well mixed with Nafion ionomer dispersion to secure proton conductivity in the layer (see Methods). The fibrous structure of the initial web was retained after grinding by hand, but with shorter fibre length 
(Figure S6a). No change was observed in the Fe K-edge XANES and FT-EXAFS spectra of EZIF-8(Fe)/PAN-Ar before and after grinding (Figure S7). This demonstrates that Fe speciation remained the same after grinding, as expected for low-energy manual grinding process. Figure S8 shows the cross section and top view SEM images of the MEA with E-ZIF-8(Fe)/PAN-Ar and ZIF-8(Fe)-Ar cathodes. The SEM micrographs clearly show the different morphologies of these two electrodes, clearly a result of the different catalyst morphologies (Figure 1 and S6). Under $\mathrm{O}_{2}, \mathrm{ZIF}-8(\mathrm{Fe})-\mathrm{Ar}$ and E-ZIF-8(Fe)/PAN-Ar exhibited a current density of 17 and 25 $\mathrm{mA} \cdot \mathrm{cm}^{-2}$ at $0.8 \mathrm{~V}$ (iR-free voltage) respectively, comparable to other ZIF-8 derived FeNC catalysts pyrolyzed in Ar. ${ }^{11}$ The $\mathrm{iR}$ correction was performed according to the average high frequency resistance measured at low and high current densities (Figure S9). However, superior mass-transport in the E-ZIF-8(Fe)/PAN-Ar cathode layer started to take effect at potentials below $0.8 \mathrm{~V}$ (Figure 4b). The current density and power density at $0.6 \mathrm{~V}$ (iR-free voltage) increased from $\sim 140 \mathrm{~mA} \cdot \mathrm{cm}^{-2}$ and $\sim 85 \mathrm{~mW} \cdot \mathrm{cm}^{-2}$ for ZIF-8(Fe)-Ar to $\sim 390 \mathrm{~mA} \cdot \mathrm{cm}^{-2}$ and $\sim 230$ $\mathrm{mW} \cdot \mathrm{cm}^{-2}$ for E-ZIF-8(Fe)/PAN-Ar (Figure 4a), due to the beneficial morphology for masstransport in the latter. While differences can be seen already with pure $\mathrm{O}_{2}$ feed at the cathode, it has been proposed that the source for mass-transport limitations of FeNC catalysts in PEMFCs is mainly from $\mathrm{O}_{2}$ rather than proton. ${ }^{16}$ Thus, we then evaluated the ORR performance of the EZIF-8(Fe)/PAN-Ar layer in $\mathrm{H}_{2}$ /air PEMFCs (Figure 4c-d). The E-ZIF-8(Fe)/PAN-Ar layer exhibited a current density of $20 \mathrm{~mA} \cdot \mathrm{cm}^{-2}$ at $0.8 \mathrm{~V}$ (iR-free voltage), which is almost two times greater than that given by ZIF-8(Fe)-Ar $\left(11 \mathrm{~mA} \cdot \mathrm{cm}^{-2}\right)$. Moreover, the current density and power density at $0.6 \mathrm{~V}$ (iR-free voltage) increased from $\sim 105 \mathrm{~mA} \cdot \mathrm{cm}^{-2}$ and $\sim 65 \mathrm{~mW} \cdot \mathrm{cm}^{-2}$ for ZIF8(Fe)-Ar to $\sim 300 \mathrm{~mA} \cdot \mathrm{cm}^{-2}$ and $\sim 180 \mathrm{~mW} \cdot \mathrm{cm}^{-2}$ for E-ZIF-8(Fe)/PAN-Ar. In summary, the PEMFC polarization curves under air and $\mathrm{O}_{2}$ both confirm the superior cathode morphology in 
E-ZIF-8(Fe)/PAN-Ar. E-ZIF-8(Fe)/PAN-Ar exhibited $\sim 30 \%$ loss in current density and power density after holding at $0.6 \mathrm{~V}$ for 50 hours (Figure S10), comparable to $36 \%$ activity loss operated at $0.55 \mathrm{~V}$ after 50 hours in $\mathrm{H}_{2} /$ air PEMFC recently reported for a ZIF-8 derived FeNC catalyst. ${ }^{51}$ State-of-the-art initial ORR activity (but lower stability) is obtained with $\mathrm{NH}_{3}$ pyrolyzed FeNC materials. ${ }^{11,17,20}$ Thus, a second pyrolysis under $\mathrm{NH}_{3}\left(900{ }^{\circ} \mathrm{C}, 15 \mathrm{~min}\right)$ was applied to E-ZIF-8(Fe)/PAN-Ar (denoted as E-ZIF-8(Fe)/PAN-ArNH 3 hereafter). The $\mathrm{NH}_{3}$ heat treatment did not alter the fibrous structure of E-ZIF-8(Fe)/PAN-Ar (Figure S6b). The enhanced ORR activity was first confirmed with RDE (Figure S4a). Then we evaluated E-ZIF8(Fe)/PAN-ArNH $\mathrm{P}_{3}$ in a $\mathrm{H}_{2} /$ air PEMFC. The current density at $0.8 \mathrm{~V}$ and $0.6 \mathrm{~V}$ (iR-free voltages) reached $\sim 55$ and $\sim 460 \mathrm{~mA} \cdot \mathrm{cm}^{-2}$, respectively. This is 1.7 and 1.5 times higher than the corresponding values obtained with E-ZIF-8(Fe)/PAN-Ar, i.e. without $\mathrm{NH}_{3}$ treatment. Comparing to the $\mathrm{H}_{2} /$ air PEMFC performances of other FeNC cathodes reported recently summarized in Table S2, the E-ZIF-8(Fe)/PAN-ArNH $\mathrm{P}_{3}$ catalyst exhibits a similar current density at $0.8 \mathrm{~V}$, and lower current density at $0.6 \mathrm{~V}$. These promising results suggest that the performance of FeNC catalysts in a practical $\mathrm{H}_{2} /$ air PEMFC can be improved by adopting a hierarchical design of the cathode layer structure. 

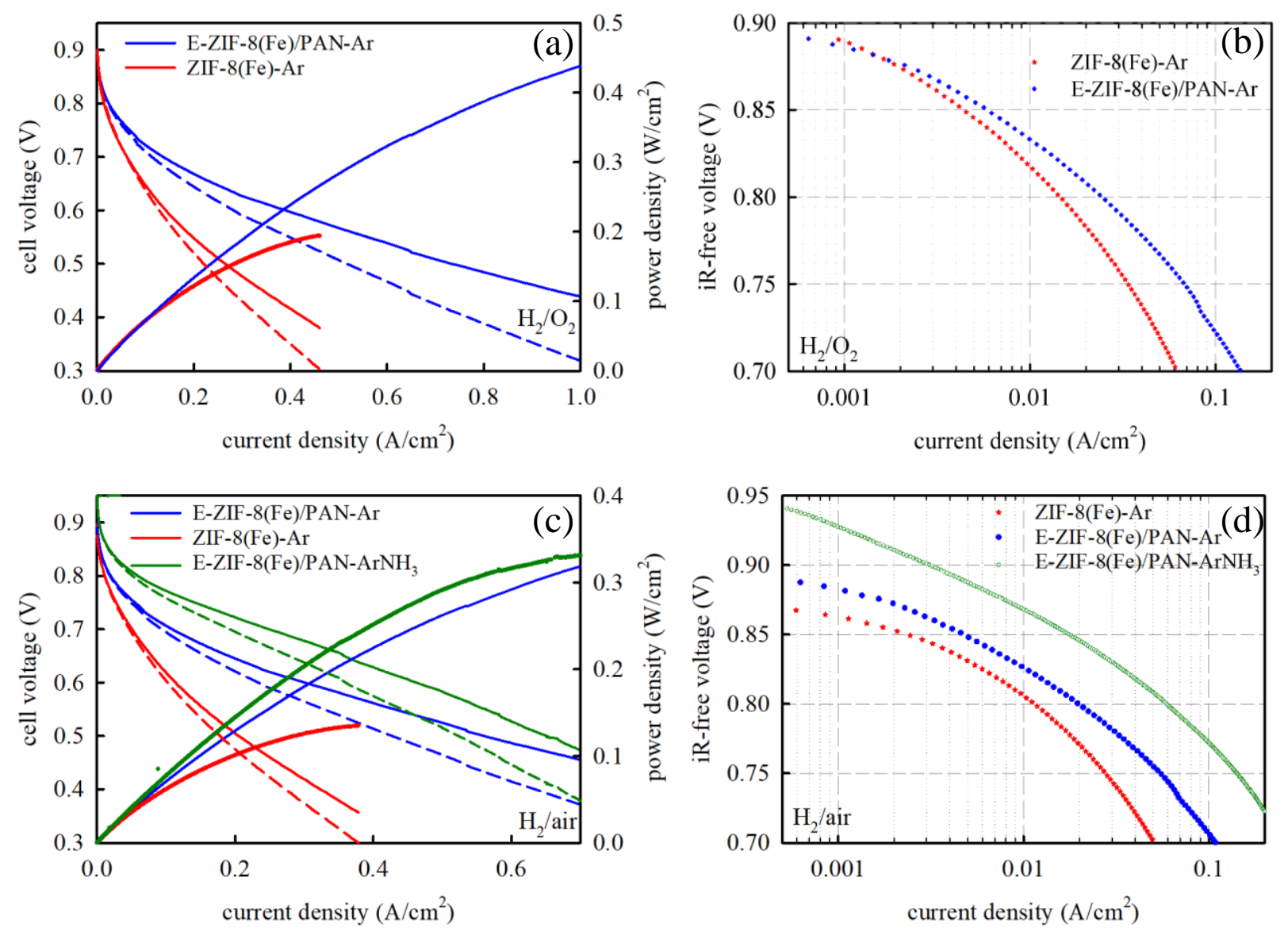

Figure 4. Electrochemical performance in single cell. (a) $\mathrm{H}_{2} / \mathrm{O}_{2}$ PEMFC polarization curves and the corresponding power density curves for MEAs with a ZIF-8(Fe)-Ar or E-ZIF8(Fe)/PAN-Ar cathode, and (b) the corresponding Tafel plots. (c) $\mathrm{H}_{2} /$ air PEMFC polarization curves and the corresponding power density curves for the same two MEAs and for a third MEA with a ZIF-8(Fe)/PAN-ArNH 3 cathode, and (d) the corresponding Tafel plots. For (a) and (c), the solid curves are iR-corrected while the dashed curves are not. The cathode loading was 4 $\mathrm{mg}_{\mathrm{FeNC}} \cdot \mathrm{cm}^{-2}$ and the anode loading was $0.5 \mathrm{mg}_{\mathrm{Pt}} \cdot \mathrm{cm}^{-2}$. The membrane was Nafion NR-211, the cell temperature was $80{ }^{\circ} \mathrm{C}$, and $\mathrm{H}_{2}(60 \mathrm{sccm}) / \mathrm{O}_{2}(60 \mathrm{sccm})$ or air $(200 \mathrm{sccm})$ were fed with $100 \%$ relative humidity. The gauge pressure was 1 bar on each side.

\subsection{Operando computed tomography}


The ex situ X-ray CT of E-ZIF-8(Fe)/PAN-Ar and ZIF-8(Fe)-Ar electrodes revealed the larger thickness of the former $(\sim 70 v s .50 \mu \mathrm{m})$ for a same catalyst loading of $4 \mathrm{mg} \cdot \mathrm{cm}^{-2}$ (Figure 5a-c and Figure S11a-c). This indicates a significantly higher volume of macropores in E-ZIF8(Fe)/PAN-Ar layer, imparted by the fibrous structure. Higher porosity in E-ZIF-8(Fe)/PAN-Ar is visible at both nano- and micro-scale (Figure 5a-c and Figure S11a-c). The porosity of each electrode can be estimated from the electrode thickness, the FeNC and Nafion loadings (4.0 and 5.7, respectively), and assuming densities of 2.0 and $1.8 \mathrm{~g} \cdot \mathrm{cm}^{-3}$ for the FeNC and Nafion phases, respectively. ${ }^{52}$ The assumed density of FeNC corresponds to that of disordered carbons. With this, the pore voids are calculated to represent $\sim 28 \%$ of the volume of the E-ZIF-8(Fe)/PAN-Ar electrode, while the pore volume in $\mathrm{ZIF}-8(\mathrm{Fe})-\mathrm{Ar}$ electrode is negligible. Operando X-ray CT was then conducted at a constant current density of $100 \mathrm{~mA} \cdot \mathrm{cm}^{-2}$ under cold-wet conditions (40$45{ }^{\circ} \mathrm{C}$ cell temperature and overhumidified gas feed), exacerbating flooding due to low water evaporation rates. ${ }^{53}$ The potential $v s$. time, polarization curves and OCV vs. time curves recorded with the cell designed for operando CT are shown in Figure S12a-c. Similar to ex situ images, operando X-ray CT images showed that E-ZIF-8(Fe)/PAN-Ar electrode is thicker than ZIF8(Fe)-Ar (Figure 5d and Figure S11d). Furthermore, the E-ZIF-8(Fe)/PAN-Ar electrode has a very homogeneous layer structure and good contact with the Nafion membrane (Figure 5d), whereas ZIF-8(Fe)-Ar has variations in the thickness and imperfect contact with the membrane that can result in proton-transport limitations at high current-densities (Figure S11d). This improved contact with Nafion membrane of E-ZIF-8(Fe)/PAN-Ar cathode may be due to a complex effect of the catalyst morphology (anisotropic fibers) during the ink drying process. At these cold-wet conditions, liquid water is expected to form within the electrode during PEMFC operation and, depending on the electrode hydrophilic properties and pore structure, either 
remains there or is moved into larger voids and under the land areas of the flow fields. ${ }^{25}$ From the X-ray CT images, liquid water was not detected in the larger voids or under the land areas, indicating that the small pores (meso and micropores) in the electrodes are intrinsically hydrophilic. This is well-known for pyrolyzed ZIF-8. The abundant water-free macroporous voids within E-ZIF-8(Fe)/PAN-Ar electrode under working conditions therefore allow the fast transportation of $\mathrm{O}_{2}$ in the gas-phase to the active sites, alleviating performance loss induced by i) too low volume of macropores in the layer (ZIF-8(Fe)-Ar), and ii) water flooding in the macropores as a result of high ORR current combined with hydrophobic meso- and micropores (possible case for other FeNC catalysts). In summary, the operando X-ray CT during fuel cell operation confirmed the improved porous structure in the E-ZIF-8(Fe)/PAN-Ar active layer, with higher macroporosity and improved contact with the Nafion membrane.
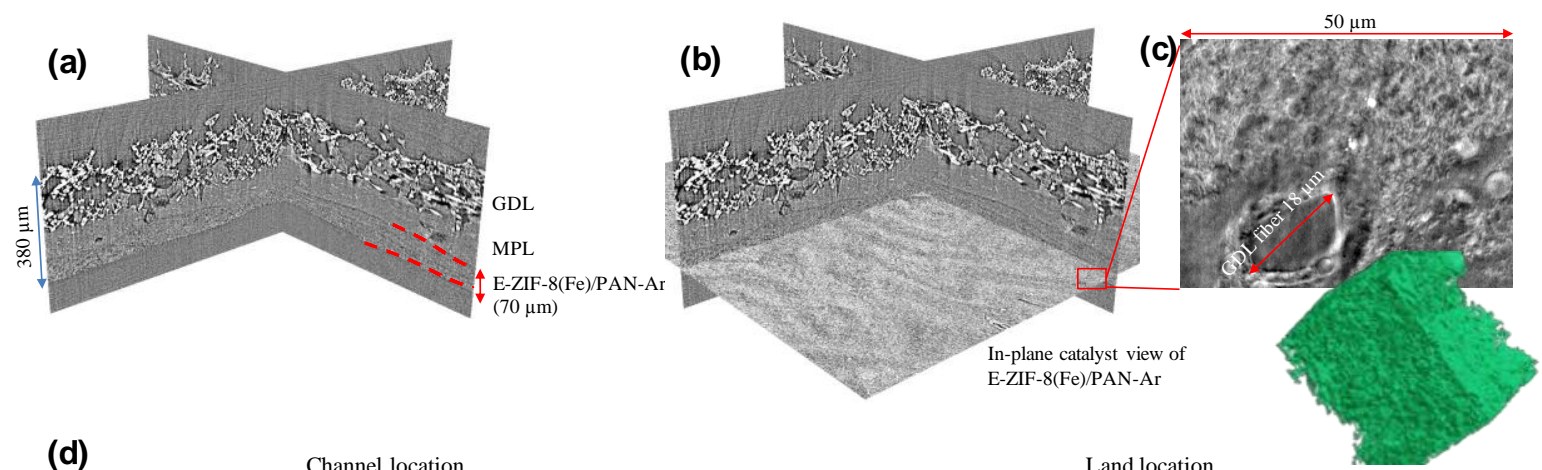

(d) Channel location
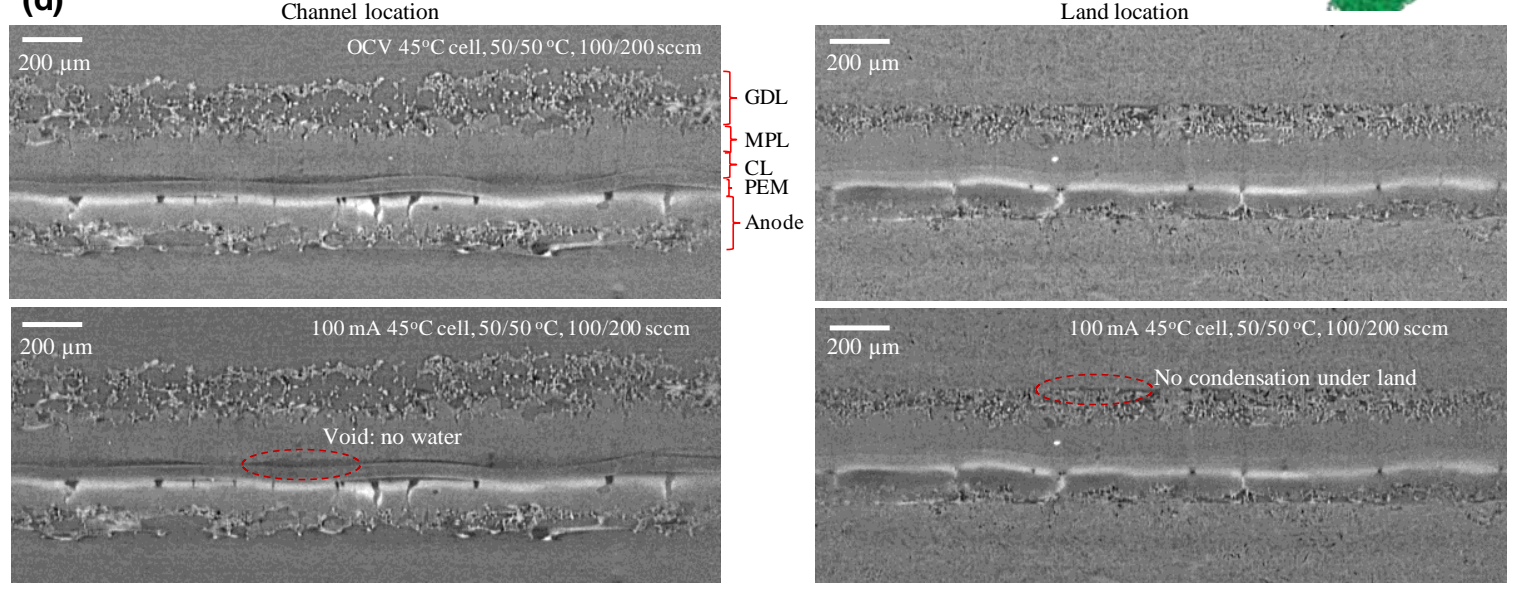
Figure 5. Ex situ and Operando X-ray CT of E-ZIF-8(Fe)/PAN-Ar electrode. (a-b) Two cross-sections from micro-CT and (c) a tomograph from nano-CT, where 3D volume-rendering is shown too. (d) $2 \mathrm{D}$ cross-sections from the $3 \mathrm{D}$ data measured in operando that correspond to location under channel (left) and under the land (right).

\section{Conclusions}

In this work, the electrospinning of nanostructured ZIF-8(Fe) is demonstrated as an effective approach to engineer the structure of FeNC catalysts, leading to a $3 \mathrm{D}$ macroporous $\mathrm{CNF}$ web with abundant intra-fibre micro- and mesopores. The macroporous voids during PEMFC operation provide a path for gas-phase diffusion of $\mathrm{O}_{2}$ to the surface of the water-filled microporous FeNC fibres, while the micropores host the $\mathrm{FeN}_{\mathrm{x}}$ sites. This rationally engineered 3D architecture of FeNC electrodes via electrospinning provides an up-scalable strategy ${ }^{54}$ to further facilitate large-scale implementation of $\mathrm{H}_{2}$ /air PEMFCs with PGM-free cathodes. However, electrospinning was also found to result, concomitantly, in the formation of metallic iron and $\mathrm{Fe}_{3} \mathrm{C}$ during pyrolysis with present synthesis approach, compromising the high density of atomically-dispersed $\mathrm{FeN}_{\mathrm{x}}$ active sites. Further efforts in our group are now devoted to take advantage of the electrospinning process for fibrous FeNC morphology, while avoiding the formation of metallic particles in FeNC fibers.

\section{Methods}

Sample preparation: Nano-sized ZIF-8(Fe) was synthesized by mixing solution A comprising $2.05 \mathrm{~g}$ of 2-methylimidazole and $1.83 \mathrm{~g}$ of butylamine in $200 \mathrm{~mL}$ methanol, and solution B comprising $2.97 \mathrm{~g}$ of $\mathrm{Zn}\left(\mathrm{NO}_{3}\right)_{2} \cdot 6 \mathrm{H}_{2} \mathrm{O}$ (Sigma-Aldrich) and $0.02 \mathrm{~g}$ of $\mathrm{FeCl}_{2} \cdot 4 \mathrm{H}_{2} \mathrm{O}$ (SigmaAldrich) in $\sim 200 \mathrm{~mL}$ methanol. Then the mixed solution was left to stand for 1 hour without 
stirring, followed by centrifugation and washing with methanol at 4,000 rpm for 6 min (3 times). For characterizing and pyrolyzing ZIF-8(Fe), the obtained paste was then dried at $70{ }^{\circ} \mathrm{C}$ overnight to obtain a pink dry powder of ZIF-8(Fe). The nano-ZIF-8 (iron-free) as a control was synthesized identically without adding $\mathrm{FeCl}_{2} \cdot 4 \mathrm{H}_{2} \mathrm{O}$. For $\mathrm{ZIF}-8(\mathrm{Fe})$ to be used in the electrospinning process, the ZIF-8(Fe)/methanol paste was washed with DMF and centrifuged at 4,000 rpm for $8 \mathrm{~min}$ ( 3 times) before drying. Then $\sim 0.2 \mathrm{~g}$ of the obtained ZIF-8(Fe)/DMF paste was carefully weighed before and after being dried in vacuum oven at $100{ }^{\circ} \mathrm{C}$ overnight to calculate the weight percentage of ZIF-8(Fe) in ZIF-8(Fe)/DMF paste (this dried powder was not used for the following electrospinning process). The ZIF-8(Fe)/DMF paste and polyacrylonitrile (PAN, Sigma-Aldrich)/DMF solution (10 wt\% PAN in DMF) was well-stirred for at least 24 hours with a magnetic stir bar, with a weight ratio of ZIF-8(Fe)/PAN of $60 / 40$. Then the homogeneous suspension of ZIF-8(Fe)/PAN in DMF was electrospun at $\sim 14 \mathrm{kV}$ with a needlecollector distance of $16 \mathrm{~cm}$ and a flow rate of $\sim 1.2 \mathrm{~mL} \cdot \mathrm{min}^{-1}$. The collector was a drum with a rotating rate set at $400 \mathrm{rpm}$ (Spraybase, Ireland). The obtained ZIF-8(Fe)/PAN fiber matt was stabilized in air at $150{ }^{\circ} \mathrm{C}$ for $120 \mathrm{~min}$, and then at $240{ }^{\circ} \mathrm{C}$ for $180 \mathrm{~min}$ with a ramp rate of 2 ${ }^{\circ} \mathrm{C} \cdot \min ^{-1}$. Then the stabilized ZIF-8(Fe)/PAN fiber matt was subjected to a pyrolysis at $1050{ }^{\circ} \mathrm{C}$ for $120 \mathrm{~min}$ in flowing Ar with a ramp rate of $4{ }^{\circ} \mathrm{C} \cdot \mathrm{min}^{-1}$. As a first control sample, ZIF-8(Fe) dry powder was directly pyrolyzed under the same condition, without stabilization in air (ZIF8(Fe)-Ar). For the highest ORR activity, the percentage of Fe in ZIF-8(Fe), and the ratio of ZIF$8(\mathrm{Fe}) / \mathrm{PAN}$ were optimized to be 1 at $\%$ and $60 / 40$ by weight, respectively.

A second control sample, ZIF-8(Fe)/PAN-Ar, was synthesized by mixing ZIF-8(Fe) and PAN in a weight ratio of 60/40 via plenary ball-milling at 400 rpm for 2 hours using zirconium jars and 
100 zirconium balls $(5 \mathrm{~mm})$ as grinding media, and then the mixture was pyrolyzed at $1050{ }^{\circ} \mathrm{C}$ for $120 \mathrm{~min}$ in flowing Ar with a ramp rate of $4{ }^{\circ} \mathrm{C} \cdot \mathrm{min}^{-1}$.

A third control sample, ZIF-8(Fe)-stabilized-Ar, was synthesized by stabilizing ZIF-8(Fe) dry powder in air at $150{ }^{\circ} \mathrm{C}$ for $120 \mathrm{~min}$, and then at $240{ }^{\circ} \mathrm{C}$ for $180 \mathrm{~min}$ with a ramp rate of 2 ${ }^{\circ} \mathrm{C} \cdot \mathrm{min}^{-1}$, and then the stabilized ZIF-8(Fe) powder was subjected to a pyrolysis at $1050{ }^{\circ} \mathrm{C}$ for $120 \mathrm{~min}$ in flowing Ar with a ramp rate of $4{ }^{\circ} \mathrm{C} \cdot \mathrm{min}^{-1}$.

SEM: Scanning electron microscopy micrographs were obtained with a Hitachi S-4800 apparatus (Hitachi, Tokyo, Japan).

Mercury intrusion porosimetry:

XRD: X-ray diffraction patterns were recorded using a PANanalytical X'Pert Pro powder X-ray diffractometer with $\mathrm{Cu} \mathrm{K} \alpha$ radiation.

$N_{2}$ adsorption/desorption: $\mathrm{N}_{2}$ adsorption/desorption was performed at liquid nitrogen temperature (77 K) with a Micromeritics ASAP 2020 instrument. Prior to the measurements, all samples were degassed at $200{ }^{\circ} \mathrm{C}$ for $5 \mathrm{~h}$ in flowing nitrogen to remove guest molecules or moisture. The pore size distributions were calculated by fitting the full isotherm with the quench solid density functional theory model with slit pore geometry from NovaWin (Quantachrome Instruments).

Raman spectroscopy: Raman spectra were collected using a LabRAM ARAMIS Raman microscope with a $473 \mathrm{~nm}$ laser. 
$X A S$ : Fe K-edge X-ray absorption spectra were collected at room temperature in transmission mode at the SAMBA beamline (Synchrotron SOLEIL). The beamline is equipped with a sagittally focusing Si 220 monochromator and two Pd-coated mirrors that were used to remove $\mathrm{X}$-ray harmonics. The catalysts were pelletized as disks of $10 \mathrm{~mm}$ diameter with $1 \mathrm{~mm}$ thickness using Teflon powder ( $1 \mu \mathrm{m}$ particle size $)$ as a binder. Data treatment were performed with the Athena software. ${ }^{55}$

${ }^{57} \mathrm{Fe}$ Mössbauer spectroscopy: 120 to $300 \mathrm{mg}$ samples were mounted in a $2 \mathrm{~cm}^{2}$ holder. The Mössbauer spectrometer (Wissel, Germany) was operated in the transmission mode with a ${ }^{57} \mathrm{Co}$ : $\mathrm{Rh}$ source at room temperature. The velocity driver was operated in the constant acceleration mode with a triangular velocity waveform. The velocity scale was calibrated with the magnetically split sextet of a high-purity $\alpha$-Fe foil at room temperature. The spectra were fitted to appropriate combinations of Lorentzian profiles representing quadrupole doublets, sextets by least-squares methods. Isomer shifts are given relative to $\alpha$-Fe at room temperature.

Electrochemical characterization-RDE: The catalyst powders were deposited on glassy carbon electrodes as working electrode. Catalyst ink was prepared by dispersing $10 \mathrm{mg}$ of the catalyst powder in a mixture of Millipore water $(36.5 \mu \mathrm{L}, 18.2 \mathrm{M} \Omega \mathrm{cm})$ and ethanol $(300 \mu \mathrm{L}$, SigmaAldrich, 99.8\%), into which $5 \mathrm{wt} \%$ Nafion solution (108.5 $\mu \mathrm{L}$, Sigma-Aldrich) was added as a binder phase. The resulting mixture was sonicated for $60 \mathrm{~min}$, and then an aliquot of $8.8 \mu \mathrm{L}$ was drop-cast onto the glassy carbon electrodes $\left(0.247 \mathrm{~cm}^{2}\right.$, Pine instrument), resulting in a loading of $800 \mu \mathrm{g} \cdot \mathrm{cm}^{-2}$. The working electrode with the deposited catalyst layer was used in a threeelectrode cell set-up connected to a bipotentiostat (Biologic SP 300) and rotator (Pine Instruments). The graphite rod and reversible hydrogen electrode (RHE) were used as counter and reference electrodes, respectively. The ORR activity was measured in $\mathrm{O}_{2}$-saturated $0.1 \mathrm{M}$ 
$\mathrm{HClO}_{4}$ from 0.05 to $1.05 \mathrm{~V}$ vs. RHE with a scan rate of $20 \mathrm{mV} \cdot \mathrm{s}^{-1}$ at $1,600 \mathrm{rpm}$. The $\mathrm{CV}$ was carried out between 0.05 to $1.05 \mathrm{~V} v s$. RHE with a scan rate of $20 \mathrm{mV} \mathrm{s}^{-1}$ in $\mathrm{N}_{2}$-saturated $0.1 \mathrm{M}$ $\mathrm{HClO}_{4}$.

Electrochemical characterization-PEMFC: The ORR activities and performance of the catalysts were also investigated in a single-cell PEMFC. For E-ZIF-8(Fe)/PAN-Ar and E-ZIF-8(Fe)/PAN$\mathrm{ArNH}_{3}$, the fibrous webs were hand-grinded into powders before use. The cathode inks were prepared by dispersing $20 \mathrm{mg}$ of catalyst powder in a mixture of Millipore water $(272 \mu \mathrm{L}$, 18.2 $\mathrm{M} \Omega \mathrm{cm})$ and ethanol (326 $\mu \mathrm{L}$, Sigma-Aldrich, 99.8\%), into which $5 \mathrm{wt} \%$ Nafion solution (652 $\mu \mathrm{L}$, Sigma-Aldrich) was added. The inks were sonicated for $60 \mathrm{~min}$. Then, three aliquots of $405 \mu \mathrm{L}$ of the catalyst ink were successively drop-cast on the microporous layer of a $4.84 \mathrm{~cm}^{2}$ gas diffusion layer (Sigracet S10-BC) to reach a catalyst loading of $4 \mathrm{mg} \cdot \mathrm{cm}^{-2}$. The cathode was then placed in a vacuum oven at $60{ }^{\circ} \mathrm{C}$ to dry for 2 hours. The anode used for all PEMFC tests performed in this work was $0.5 \mathrm{mg}_{\mathrm{Pt}} \cdot \mathrm{cm}^{-2}$ on Sigracet S10-BC. Membrane electrode assemblies (MEAs) were prepared by hot-pressing a $4.84 \mathrm{~cm}^{2}$ anode and cathode against either side of a Nafion NRE-211 membrane at $136{ }^{\circ} \mathrm{C}$ for 2 min. PEMFC characterization was performed with a single-cell fuel cell with serpentine flow field (Fuel Cell Technologies) using an in-house fuel cell test stand and a Biologic Potentiostat with a 50 A load and EC-Lab software. For the tests, the fuel cell temperature was $80{ }^{\circ} \mathrm{C}$, the humidifiers were set at $85{ }^{\circ} \mathrm{C}$, and the inlet pressures were set to 1 bar gauge for both anode and cathode sides. The flow rates for humidified $\mathrm{H}_{2} / \mathrm{O}_{2}$ and $\mathrm{H}_{2} /$ air were 60/60 and 60/200 sccm (downstream of the fuel cell), respectively. Polarization curves were recorded by scanning the cell voltage at $0.5 \mathrm{mV} \cdot \mathrm{s}^{-1}$, which is sufficiently low to neglect any capacitive current. 
Operando computed tomography: Micro X-ray CT imaging was performed at the Advanced Light Source (ALS) at Lawrence Berkeley National Laboratory (LBNL), at Beamline 8.3.2. Monochromatic X-rays at $25 \mathrm{keV}$ were selected with a double-multilayer monochromator. Pixel size of 1.3 um was achieved with $5 x$ lenses with a sCMOS PCO Edge camera and $0.5 \mathrm{~mm} \mathrm{LuAG}$ scintillator. The achieved horizontal field-of-view (FOV) was $3.3 \mathrm{~mm}$, vertical FOV depends on energy and is smaller than that. Two FOV were collected per cell with 700 ms per projection and 1040 projections total. Earlier version of operando fuel cell hardware is reported in previous study. ${ }^{25}$ Here we provide only salient details. The cell active area is $1 \mathrm{~cm}^{2}(2 \mathrm{~cm} \times 0.5 \mathrm{~cm})$, the MEA is sandwiched between two bipolar plates that have two parallel channels $(1 \mathrm{~mm} \times 1 \mathrm{~mm})$. The MEA composition was the same as reported in the above section. The aluminum clamps are used for compression on the top and bottom of the cell, whereas the $1 \mathrm{~cm}^{2}$ of area used for imaging has only graphite bipolar plates for high X-ray transmission. Hard-stop gaskets are used to achieve $20 \%$ cell compression. Mass-flow controllers and external humidifiers are used for humidity control. Nano X-ray CT for ex-situ samples was performed at beamline 32-ID at Advanced Photon Source (APS) at Argonne National Laboratory (ANL). Monochromatic X-rays at $8 \mathrm{keV}$ were selected for imaging. Phase-ring was used behind Fresnel zone plate to image carbon materials. The FOV was $75 \times 75 \mu \mathrm{m}$ and resolution $60 \mathrm{~nm}$. 1500 projections were recorded with $1 \mathrm{~s}$ per projection, resulting in approximately 20 min scan. Raw data was reconstructed using TomoPy software, Gridrec algorithm was used for tomographic reconstructions. Reconstructions parameters were reported earlier. ${ }^{56}$ For nano-CT reconstructions phase retrieval and tomographic reconstructions were performed using TomoPy and ASTRA..$^{5760}$ ImageJ was used for image analysis and a combination of ImageJ and Avizo for data visualization. 


\section{Supporting Information.}

The following files are available free of charge.

FT-IR (a) and FT-far-IR (b) spectra of ZIF-8(Fe); SEM images of E-ZIF-8(Fe)/PAN fibers before pyrolysis, E-ZIF-8(Fe)/PAN-Ar and E-ZIF-8(Fe)/PAN-ArNH 3 after grinding, and their electrode top-view and MEA cross section view; the pore size distributions of E-ZIF-8(Fe)/PANAr and ZIF-8(Fe)-Ar measured by mercury intrusion porosimetry; Fe K-edge XANES spectra (a) and FT-EXAFS spectra (b) of E-ZIF-8(Fe)/PAN-Ar before and after grinding; the electrochemistry profiles of E-ZIF-8(Fe)/PAN-Ar and E-ZIF-8(Fe)/PAN-ArNH ${ }_{3}$, the current density and power density $v s$. time of E-ZIF-8(Fe)/PAN-Ar during a $0.6 \mathrm{~V}$ potential hold (non-iR corrected) in $\mathrm{H}_{2}$ /air PEMFC; ex-situ and operando X-ray CT of ZIF-8(Fe)-Ar and the corresponding electrochemistry profiles; the discussion about parameters of the doublet in ${ }^{57} \mathrm{Fe}$ Mössbauer spectra; the surface area obtained with $\mathrm{N}_{2}$ physisorption analysis; and a table summarizing the $\mathrm{H}_{2}$ /air PEMFC performance for FeNC cathodes from literature (PDF)

\section{AUTHOR INFORMATION}

\section{Corresponding Author}

*Jingkun Li: jingkun.li@umontpellier.fr

*Sara Cavaliere: sara.cavaliere@umontpellier.fr

*Frédéric Jaouen: frederic.jaouen@umontpellier.fr

\section{Author Contributions}

The manuscript was written through contributions of all authors. All authors have given approval to the final version of the manuscript. 


\section{ACKNOWLEDGMENT}

The research leading to these results has received funding from the French National Research Agency under the CAT ${ }^{2}$ CAT contract (ANR-16-CE05-0007). SC also acknowledges the financial support from the European Research Council under the European Union's Seventh Framework Programme (FP/2007-2013)/ERC Grant Agreement n. 306682 and the French IUF. I. V. Z. acknowledges support from the National Science Foundation under CBET Award 1605159. We thank Mr. Andrew Shum, Dr. Vincent DeAndrade and Dr. Dula Parkinson for support with X-ray CT data collection and reconstructions. The Advanced Light Source is supported by the Director, Office of Science, Office of Basic Energy Sciences, of the U.S. Department of Energy under Contract No. DE-AC02-05CH11231. This research used resources of the Advanced Photon Source, a U.S. Department of Energy (DOE) Office of Science User Facility operated for the U.S. DOE Office of Science by Argonne National Laboratory under Contract No. DE-AC0206CH11357. We acknowledge Synchrotron SOLEIL (Gif-sur Yvette, France) for provision of synchrotron radiation facilities at beamline SAMBA (proposal number 20180635).

\section{REFERENCES}

1. Chattot, R.; Le Bacq, O.; Beermann, V.; Kühl, S.; Herranz, J.; Henning, S.; Kühn, L.; Asset, T.; Guétaz, L.; Renou, G.; Drnec, J.; Bordet, P.; Pasturel, A.; Eychmüller, A.; Schmidt, T. J.; Strasser, P.; Duban, L.; Mailard, F. Surface Distortion as a Unifying Concept and Descriptor in Oxygen Reduction Reaction Electrocatalysis. Nat. Mater. 2018, 17, 827-833.

2. Chong, L.; Wen, J.; Kubal, J.; Sen, F. G.; Zou, J.; Greeley, J.; Chan, M.; Barkholtz, H.; Ding, W.; Liu, D.-J. Ultralow-Loading Platinum-Cobalt Fuel Cell Catalysts Derived from Imidazolate Frameworks. Science 2018, 362, 1276-1281.

3. Huang, X.; Zhao, Z.; Cao, L.; Chen, Y.; Zhu, E.; Lin, Z.; Li, M.; Yan, A.; Zettl, A.; Wang, Y. M.; Duan, X.; Mueller, T.; Huang, Y. High-Performance Transition Metal-Doped $\mathrm{Pt}_{3} \mathrm{Ni}$ Octahedra for Oxygen Reduction Reaction. Science 2015, 348, 1230-1234.

4. Stamenkovic, V. R.; Fowler, B.; Mun, B. S.; Wang, G.; Ross, P. N.; Lucas, C. A.; Marković, N. M. Improved Oxygen Reduction Activity on $\mathrm{Pt}_{3} \mathrm{Ni}$ (111) via Increased Surface Site Availability. Science 2007, 315, 493-497.

5. Shao, M.; Chang, Q.; Dodelet, J.-P.; Chenitz, R. Recent Advances in Electrocatalysts for Oxygen Reduction Reaction. Chem. Rev. 2016, 116, 3594-3657.

6. Gewirth, A. A.; Varnell, J. A.; Diascro, A. M. Nonprecious Metal Catalysts for Oxygen 
Reduction in Heterogeneous Aqueous Systems. Chem. Rev. 2018, 118, 2313-2339.

7. Li, J.; Jaouen, F. Structure and Activity of Metal-Centered Coordination Sites in Pyrolyzed Metal-Nitrogen-Carbon Catalysts for the Electrochemical Reduction of $\mathrm{O}_{2}$. Current Opinion in Electrochemistry 2018, 9, 198-206.

8. He, D.; Xiong, Y.; Yang, J.; Chen, X.; Deng, Z.; Pan, M.; Li, Y.; Mu, S. NanocarbonIntercalated and Fe-N-Codoped Graphene as a Highly Active Noble-Metal-Free Bifunctional Electrocatalyst for Oxygen Reduction and Evolution. J. Mater. Chem. A 2017, 5, 1930-1934.

9. Zhang, J.; Li, Q.; Wu, H.; Zhang, C.; Cheng, K.; Zhou, H.; Pan, M.; Mu, S. Nitrogen-SelfDoped Carbon with a Porous Graphene-Like Structure as a Highly Efficient Catalyst for Oxygen Reduction. J. Mater. Chem. A 2015, 3, 10851-10857.

10. Jasinski, R. A New Fuel Cell Cathode Catalyst. Nature 1964, 201, 1212-1213.

11. Zitolo, A.; Goellner, V.; Armel, V.; Sougrati, M.-T.; Mineva, T.; Stievano, L.; Fonda, E.; Jaouen, F. Identification of Catalytic Sites for Oxygen Reduction in Iron-and Nitrogen-Doped Graphene Materials. Nat. Mater. 2015, 14, 937-942.

12. Zitolo, A.; Ranjbar-Sahraie, N.; Mineva, T.; Li, J.; Jia, Q.; Stamatin, S.; Harrington, G. F.; Lyth, S. M.; Krtil, P.; Mukerjee, S.; Fonda, E.; Jaouen, F. Identification of Catalytic Sites in Cobalt-Nitrogen-Carbon Materials for the Oxygen Reduction Reaction. Nat Commun. 2017, 8, 957.

13. Wang, X. X.; Swihart. M. T.; Wu, G. Achievements, Challenges and Perspectives on Cathode Catalysts in Proton Exchange Membrane Fuel Cells for Transportation. Nat. Catal. 2019, 2, 578589.

14. Chung, H. T.; Cullen, D. A.; Higgins, D.; Sneed, B. T.; Holby, E. F.; More, K. L.; Zelenay, P. Direct Atomic-Level Insight into the Active Sites of A High-Performance PGM-Free ORR Catalyst. Science 2017, 357, 479-484.

15. Kumar, K.; Gairola, P.; Lions, M.; Ranjbar-Sahraie, N.; Mermoux, M.; Dubau, L.; Zitolo, A.; Jaouen, F.; Maillard, F. Physical and Chemical Considerations for Improving Catalytic Activity and Stability of Non-Precious-Metal Oxygen Reduction Reaction Catalysts. ACS Catal. 2018, 8, 11264-11276.

16. Banham, D.; Kishimoto, T.; Zhou, Y.; Sato, T.; Bai, K.; Ozaki, J.-i.; Imashiro, Y.; Ye, S. Critical Advancements in Achieving High Power and Stable Nonprecious Metal Catalyst-Based MEAs for Real-World Proton Exchange Membrane Fuel Cell Applications. Sci. Adv. 2018, 4, 7180 .

17. Li, J.; Ghoshal, S.; Liang, W.; Sougrati, M.-T.; Jaouen, F.; Halevi, B.; McKinney, S.; McCool, G.; Ma, C.; Yuan, X. J.; Ma, Z.-F. ; Mukerjee, S.; Jia, Q. Structural and Mechanistic Basis for the High Activity of Fe-N-C Catalysts Toward Oxygen Reduction. Energy Environ. Sci. 2016, 9, 2418-2432.

18. Kramm, U. I.; Herrmann-Geppert, I.; Behrends, J.; Lips, K.; Fiechter, S.; Bogdanoff, P. On An Easy Way to Prepare Metal-Nitrogen Doped Carbon with Exclusive Presence of $\mathrm{MeN}_{4}$-Type Sites Active for the ORR. J. Am. Chem. Soc. 2016, 138, 635-640.

19. Jaouen, F.; Lefèvre, M.; Dodelet, J.-P.; Cai, M. Heat-treated Fe/N/C Catalysts for $\mathrm{O}_{2}$ Electroreduction: Are Active Sites Hosted in Micropores? J. Phys. Chem. B 2006, 110, 55535558.

20. Proietti, E.; Jaouen, F.; Lefèvre, M.; Larouche, N.; Tian, J.; Herranz, J.; Dodelet, J.-P. Iron-Based Cathode Catalyst with Enhanced Power Density in Polymer Electrolyte Membrane Fuel Cells. Nat. Commun. 2011, 2, 416.

21. Wang, Z.; Jin, H.; Meng, T.; Liao, K.; Meng, W.; Yang, J.; He, D.; Xiong, Y.; Mu, S. Fe, 
Cu-Coordinated ZIF-Derived Carbon Framework for Efficient Oxygen Reduction Reaction and Zinc-Air Batteries. Adv. Funct. Mater. 2018, 28, 1802596.

22. Jin, H.; Zhou, H.; He, D.; Wang, Z.; Wu, Q.; Liang, Q.; Liu, S.; Mu, S. MOF-Derived 3D Fe-N-S Co-Doped Carbon Matrix/Nanotube Nanocomposites with Advanced Oxygen Reduction Activity and Stability in Both Acidic and Alkaline Media. Appl. Catal. B: Environ. 2019, 250, 143-149.

23. Jin, H.; Zhou, H.; Li, W.; Wang, Z.; Yang, J.; Xiong, Y.; He, D.; Chen, L.; Mu, S. In Situ Derived Fe/N/S-Codoped Carbon Nanotubes from ZIF-8 Crystals as Efficient Electrocatalysts for the Oxygen Reduction Reaction and Zinc-Air Batteries. J. Mater. Chem. A 2018, 6, 2009320099.

24. Shi, X.; Huang, T. Effect of Pore-Size Distribution in Cathodic Gas Diffusion Layers on the Electricity Generation of Microbial Fuel Cells (MFCs). RSC Adv. 2015, 5, 102555-102559.

25. Normile, S. J.; Sabarirajan, D. C.; Calzada, O.; De Andrade, V.; Xiao, X.; Mandal, P.; Parkinson, D. Y.; Serov, A.; Atanassov, P.; Zenyuk, I. V. Direct Observations of Liquid Water Formation at Nano- and Micro-Scale in Platinum Group Metal-Free Electrodes by Operando XRay Computed Tomography. Mater. Today Energy 2018, 9, 187-197.

26. Serov, A.; Shum, A. D.; Xiao, X.; De Andrade, V.; Artyushkova, K.; Zenyuk, I. V.; Atanassov, P. Nano-Structured Platinum Group Metal-Free Catalysts and Their Integration in Fuel Cell Electrode Architectures. Appl. Catal. B. 2017, 237, 1139-1147.

27. Martinez, U.; Babu, S. K.; Holby, E. F.; Zelenay, P. Durability Challenges and Perspective in the Development of PGM-Free Electrocatalysts for the Oxygen Reduction Reaction. Current Opinion in Electrochemistry 2018, 9, 224-232.

28. Martinez, U.; Komini Babu, S.; Holby, E. F.; Chung, H. T.; Yin, X.; Zelenay, P. Progress in the Development of Fe-Based PGM-Free Electrocatalysts for the Oxygen Reduction Reaction. Adv. Mater. 2019, 1806545.

29. Choi, C. H.; Lim, H.-K.; Chung, M. W.; Chon, G.; Sahraie, N. R.; Altin, A.; Sougrati, M.T.; Stievano, L.; Oh, H. S.; Park, E. S.; Luo, F.; Strasser, P.; Dražić, G.; Mayrhofer, K. J. J.; Kim, H.; Jaouen, F. The Achilles' Heel of Iron-Based Catalysts During Oxygen Reduction in An Acidic Medium. Energy Environ. Sci. 2018, 11, 3176-3182.

30. Shao, Y.; Dodelet, J.-P.; Wu, G.; Zelenay, P. PGM-Free Cathode Catalysts for PEM Fuel Cells: A Mini-Review on Stability. Adv. Mater. 2019, 1807615.

31. Slack, J.; Halevi, B.; McCool, G.; Li, J.; Pavlicek, R.; Wycisk, R.; Mukerjee, S.; Pintauro, P. Electrospun Fiber Mat Cathode with Platinum-Group-Metal-Free Catalyst Powder and Nafion/PVDF Binder. ChemElectroChem 2018, 5, 1537-1542.

32. Shui, J.; Chen, C.; Grabstanowicz, L.; Zhao, D.; Liu, D.-J. Highly Efficient Nonprecious Metal Catalyst Prepared with Metal-Organic Framework in A Continuous Carbon Nanofibrous Network. Proc. Natl. Acad. Sci. U.S.A. 2015, 112, 10629-10634.

33. Zhang, C.-L.; Lu, B.-R.; Cao, F.-H.; Wu, Z.-Y.; Zhang, W.; Cong, H.-P.; Yu, S.-H. Electrospun Metal-Organic Framework Nanoparticle Fibers and Their Derived Electrocatalysts for Oxygen Reduction Reaction. Nano Energy 2019, 55, 226-233.

34. Zhang, H.; Zhou, W.; Chen, T.; Guan, B. Y.; Li, Z.; Lou, X. W. A Modular Strategy for Decorating Isolated Cobalt Atoms into Multichannel Carbon Matrix for Electrocatalytic Oxygen Reduction. Energy Environ. Sci. 2018, 11, 1980-1984.

35. Wang, M.; Zhang, C.; Meng, T.; Pu, Z.; Jin, H.; He, D.; Zhang, J.; Mu, S. Iron Oxide and Phosphide Encapsulated within N, P-Doped Microporous Carbon Nanofibers as Advanced Tri- 
Functional Electrocatalyst Toward Oxygen Reduction/Evolution and Hydrogen Evolution Reactions and Zinc-Air Batteries. J. Power Sources 2019, 413, 367-375.

36. Zhang, H.; Hwang, S.; Wang, M.; Feng, Z.; Karakalos, S.; Luo, L.; Qiao, Z.; Xie, X.; Wang, C.; Su, D., Shao, Y.; Wu, G. Single Atomic Iron Catalysts for Oxygen Reduction in Acidic Media: Particle Size Control and Thermal Activation. J. Am. Chem. Soc. 2017, 139, 1414314149.

37. Armel, V.; Hannauer, J.; Jaouen, F. Effect of ZIF-8 Crystal Size on the $\mathrm{O}_{2}$ Electro-Reduction Performance of Pyrolyzed Fe-N-C Catalysts. Catalysts 2015, 5, 1333-1351.

38. Ercolano, G.; Farina, F.; Cavaliere, S.; Jones, D. J.; Rozière, J. Towards Ultrathin Pt Films on Nanofibres by Surface-Limited Electrodeposition for Electrocatalytic Applications. J Mater. Chem. A 2017, 5, 3974-3980.

39. Yarova, S.; Jones, D.; Jaouen, F.; Cavaliere, S. Strategies to Hierarchical Porosity in Carbon Nanofiber Webs for Electrochemical Applications. Surfaces 2019, 2, 159-176.

40. Kramm, U. I.; Lefèvre, M.; Larouche, N.; Schmeisser, D.; Dodelet, J.-P. Correlations between Mass Activity and Physicochemical Properties of Fe/N/C Catalysts for the ORR in PEM Fuel Cell via ${ }^{57} \mathrm{Fe}$ Mossbauer Spectroscopy and Other Techniques. J. Am. Chem. Soc. 2014, 136, 978-985.

41. Mineva, T.; Matanovic, I.; Atanassov, P.; Sougrati, M. T.; Stievano, L.; Clémancey, M.; Kochem, A.; Latour, J.-M.; Jaouen, F. Understanding Active Sites in Pyrolyzed Fe-NC Catalysts for Fuel Cell Cathodes by Bridging Density Functional Theory Calculations and ${ }^{57} \mathrm{Fe}$ Mössbauer Spectroscopy. ACS Catal. 2019, DOI:10.1021/acscatal.9b02586.

42. Wagner, S.; Auerbach, H.; Tait, C. E.; Martinaiou, I.; Kumar, S. C. N.; Kübel, C.; Sergeev, I.; Wille, H.-C.; Behrends, J.; Wolny, J. A.; Schünemann, V.; Kramm, U. I. Elucidating the Structural Composition of a Fe-N-C Catalyst by Nuclear and Electron Resonance Techniques. Angew. Chem. Int. Ed. 2019, 58, 10586-10492.

43. Qu, Y.; Li, Z.; Chen, W.; Lin, Y.; Yuan, T.; Yang, Z.; Zhao, C.; Wang, J.; Zhao, C.; Wang, X.; Zhou, F.; Zhuang, Z.; Wu, Y.; Li, Y. Direct Transformation of Bulk Copper into Copper Single Sites via Emitting and Trapping of Atoms. Nat. Catal. 2018, 1, 781-786.

44. Wei, S.; Li, A.; Liu, J.-C.; Li, Z.; Chen, W.; Gong, Y.; Zhang, Q.; Cheong, W.-C.; Wang, Y.; Zheng, L. Xiao, H.; Chen, C.; Wang, D.; Peng, Q.; Gu, L.; Han, X.; Li, J.; Li, Y. Direct Observation of Noble Metal Nanoparticles Transforming to Thermally Stable Single Atoms. Nat. Nanotechnol. 2018, 13, 856-861.

45. Kramm, U. I.; Herranz, J.; Larouche, N.; Arruda, T. M.; Lefèvre, M.; Jaouen, F.; Bogdanoff, P.; Fiechter, S.; Abs-Wurmbach, I.; Mukerjee, S.; Dodelet J.-P. Structure of the Catalytic Sites in Fe/N/C-Catalysts for $\mathrm{O}_{2}$-Reduction in PEM Fuel Cells. Phys. Chem. Chem. Phys. 2012, 14, 11673-11688.

46. Li, J.; Jia, Q.; Mukerjee, S.; Sougrati, M.-T.; Drazic, G.; Zitolo, A.; Jaouen, F. The Challenge of Achieving A High Density of Fe-Based Active Sites in a Highly Graphitic Carbon Matrix. Catalysts 2019, 9, 144.

47. James, J. B.; Lin, Y. S. Kinetics of ZIF-8 Thermal Decomposition in Inert, Oxidizing, and Reducing Environments. J. Phys. Chem. C 2016, 120, 14015-14026.

48. Ahn, B. W.; Kang, T. J. Preparation and Characterization of Magnetic Nanofibers with Iron Oxide Nanoparticles and Poly(Ethyene Terphthalate). J. Appl. Polym. Sci. 2012, 125, 1567-1575.

49. Dodelet, J. P.; Chenitz, R.; Yang, L.; Lefèvre, M. A New Catalytic Site for the Electroreduction of Oxygen? ChemCatChem 2014, 6, 1866-1867.

50. Chlistunoff, J. RRDE and Voltammetric Study of ORR on Pyrolyzed Fe/Polyaniline Catalyst: 
On the Origins of Variable Tafel Slopes. J. Phys. Chem. C 2011, 115 (14), 6496-6507.

51. Zhang, H.; Chung, H. T.; Cullen, D. A.; Wagner, S.; Kramm, U. I.; More, K. L.; Zelenay, P.; Wu, G. High-Performance Fuel Cell Cathodes Exclusively Containing Atomically Dispersed Iron Active Sites. Energy Environ. Sci. 2019, 12, 2548-2558.

52. Ihonen, J.; Jaouen, F.; Lindbergh, G.; Lundblad, A.; Sundholm, G. Investigation of MassTransport Limitations in the Solid Polymer Fuel Cell Cathode II. Experimental. J. Electrochem. Soc. 2002, 149, A448-A454.

53. Zenyuk, I. V.; Lamibrac, A.; Eller, J.; Parkinson, D. Y.; Marone, F.; Büchi, F. N.; Weber, A. Z. Investigating Evaporation in Gas Diffusion Layers for Fuel Cells with X-Ray Computed Tomography. J. Phys. Chem. C 2016, 120, 28701-28711.

54. Persano, L.; Camposeo, A.; Tekmen, C.; Pisignano, D. Industrial Upscaling of Electrospinning and Applications of Polymer Nanofibers: A Review. Macromol. Mater. Eng. 2013, 298, 504-520.

55. Ravel, B.; Newville, M. ATHENA, ARTEMIS, HEPHAESTUS: Data Analysis for X-Ray Absorption Spectroscopy Using IFEFFIT. J. Synchrotron Rad. 2005, 12, 537-541.

56. Serov, A.; Shum, A. D.; Xiao, X.; De Andrade, V.; Artyushkova, K.; Zenyuk, I. V.; Atanassov, P. Nano-Structured Platinum Group Metal-Free Catalysts and Their Integration in Fuel Cell Electrode Architectures. Appl. Catal. B 2018, 237, 1139-1147.

57. Gürsoy, D.; De Carlo, F.; Xiao, X.; Jacobsen, C. TomoPy: A Framework for the Analysis of Synchrotron Tomographic Data. J. Synchrotron Rad. 2014, 21, 1188-1193.

58. Pelt, D. M.; Gürsoy, D.; Palenstijn, W. J.; Sijbers, J.; De Carlo, F.; Batenburg, K. J. Integration of TomoPy and the ASTRA Toolbox for Advanced Processing and Reconstruction of Tomographic Synchrotron Data. J. Synchrotron Rad. 2016, 23, 842-849.

59. De Carlo, F.; Gürsoy, D.; Marone, F.; Rivers, M.; Parkinson, D. Y.; Khan, F.; Schwarz, N.; Vine, D. J.; Vogt, S.; Gleber, S.-C., Narayanan, S.; Newville, M.; Lanzirotti, T.; Sun, Y.; Hong, Y. P.; Jacobsen, C. Scientific Data Exchange: a Schema for HDF5-Based Storage of Raw and Analyzed Data. J. Synchrotron Rad. 2014, 21, 1224-1230.

60. De Andrade, V.; Deriy, A.; Wojcik, M. J.; Gürsoy, D.; Shu, D.; Fezzaa, K.; De Carlo, F. Nanoscale 3D Imaging at the Advanced Photon Source. SPIE Newsroom, 2016, 2-4. 